\title{
QUEEN'S
UNIVERSITY
BELFAST
}

\section{How does layered heterogeneity affect the ability of subsurface dams to clean up coastal aquifers contaminated with seawater intrusion?}

Abdoulhalik, A., \& Ahmed, A. A. (2017). How does layered heterogeneity affect the ability of subsurface dams to clean up coastal aquifers contaminated with seawater intrusion ? Journal of Hydrology, 553, 708-721.

https://doi.org/10.1016/j.jhydrol.2017.08.044

Published in:

Journal of Hydrology

Document Version:

Peer reviewed version

Queen's University Belfast - Research Portal:

Link to publication record in Queen's University Belfast Research Portal

Publisher rights

(C) 2017 Elsevier Ltd.

This manuscript is distributed under a Creative Commons Attribution-NonCommercial-NoDerivs License

(https://creativecommons.org/licenses/by-nc-nd/4.0/), which permits distribution and reproduction for non-commercial purposes, provided the author and source are cited.

\section{General rights}

Copyright for the publications made accessible via the Queen's University Belfast Research Portal is retained by the author(s) and / or other copyright owners and it is a condition of accessing these publications that users recognise and abide by the legal requirements associated with these rights.

Take down policy

The Research Portal is Queen's institutional repository that provides access to Queen's research output. Every effort has been made to ensure that content in the Research Portal does not infringe any person's rights, or applicable UK laws. If you discover content in the Research Portal that you believe breaches copyright or violates any law, please contact openaccess@qub.ac.uk. 


\section{How does layered heterogeneity affect the ability of subsurface dams to clean up coastal} aquifers contaminated with seawater intrusion?

Antoifi Abdoulhalik ${ }^{1}$ and Ashraf A. Ahmed ${ }^{1, *}$

${ }^{1}$ School of Natural and Built Environment, Queen's University Belfast, David Keir Building, Stranmillis Road, Belfast, BT95AG, UK

\section{Abstract}

The main purpose of this work was to examine how aquifer layering impacts the ability of subsurface dams to retain seawater intrusion (SWI) and to clean up contaminated coastal aquifers using both experimental and numerical techniques. Four different layering configurations were investigated, including a homogeneous case (case $\mathrm{H}$ ), and three different layered cases where a low permeability layer was set at the top of the aquifer (case LH), at the middle part of the aquifer as interlayer (case HLH), and at the lower part of the aquifer (case HL). The subsurface dam was able to retain the saltwater wedge associated with a drop of the hydraulic gradient from 0.0158 down to 0.0095 in all the cases, thereby achieving up to $78 \%$ reduction in the saltwater toe length. In cases LH and HLH, the start of the saltwater spillage was delayed compared to the homogeneous case, and the time taken for the freshwater zone to be fully contaminated (post-spillage) was twice and three times longer, respectively. By contrast, the existence of a low $\mathrm{K}$ layer at the bottom of the aquifer (case HL) considerably weakened the ability of dams to retain the intrusion, allowing for quicker saltwater spillage past the wall. The natural cleanup of SWI-contaminated coastal aquifers was, for the first time, evidenced in heterogeneous settings. Depending on the stratification pattern, the presence of stratified layers however prolonged the cleanup time to various degrees, compared to the homogeneous scenario, particularly in case HL, where the cleanup time was nearly $50 \%$ longer.

\footnotetext{
*Corresponding Author: Ashraf Ahmed Email: a.ahmed@qub.ac.uk
} 
Keywords: Subsurface physical barriers; Coastal aquifer management; Laboratory experiments; SEAWAT; Aquifer Remediation; Subsurface heterogeneity

\section{Introduction}

With the increasing water demand, the management of coastal aquifers has been a primordial source of distress for coastal populations. Coastal aquifers represent natural underground storage of fresh groundwater located along the shores. While these constitute vital sources of water supply for people living along the shores, they remain very sensitive to degradation due to their proximity with oceanic seawater, specifically to seawater intrusion, which refers to the subsurface movement of seawater into the fresh groundwater. Factors such as groundwater pumping, intermittent sea level fluctuations (e.g. tides) as well as global warming may alter the natural groundwater hydraulic gradient and amplify the intrusion process. The primary adverse effects of SWI are the reduction of the available freshwater volume as well as the abandonment of contaminated production wells. Mixing the fresh groundwater with only 3$4 \%$ of saltwater is enough to render it unsuitable for drinking or irrigation purposes and rising this to $6 \%$ will render the groundwater unfit for all purposes except for cooling (Morris et al., 2003).

The preservation of groundwater quality in coastal areas has promoted the deployment of various practical engineering applications affecting the hydrodynamic of the aquifer, through physical alteration of the aquifer and/or groundwater recharge (Werner et al., 2013). Amongst these are the underground barriers, which are essentially impermeable walls constructed along the seashores, by way of grouting low permeability material to obstruct the inland motion of the saline plume and protect groundwater resources. The use of physical barriers as a SWI control method has been the focus of several studies (Archwichai et al., 2005; Sugio et al., 1987; Anwar, 1983; Kaleris and Ziogas, 2013; Luyun et al., 2009; Strack et al., 2016; 
Abdoulhalik and Ahmed, 2017; Abdoulhalik et al., 2017). The two main types of physical barriers include the subsurface dam and the cutoff wall. The first type is set in the lower part of the aquifer while an opening is left in the upper part for the seaward freshwater discharge, thereby physically obstructing the inland penetration of saline water. The second type of barrier covers the upper part of the aquifer, while an opening is left at the bottom through which freshwater flows at higher velocity.

Abdoulhalik et al. (2017) recently proposed a new barrier system called mixed physical barrier (MPB), which consists in the simultaneous application of a cutoff wall and semipermeable dam. Their results show that the MPB caused a visible saltwater lifting process whereby freshwater flowing below the wall opening with increased velocity transported dispersive flux of salt above the subsurface dam and discharged it towards the outlet. This lifting mechanism yielded significant reduction of the intrusion length. Strack et al. (2016) recently suggested an excavation-free method of barrier installation, which consists in reducing the hydraulic conductivity of the upper part of the aquifer by injecting precipitate at the surface downstream from production wells to mitigate SWI. The appraisal of the practicality of this method in field application needs nevertheless further investigations.

The viability of physical barriers has been discussed in previous studies (e.g. Hasan Basri, 2001; Sugio et al., 1987). Hasan Basri (2001) suggested two methods for optimal design of subsurface dams to increase the cost-effectiveness of the implementation of this countermeasure. This type of barrier has met a great success in Japan, where advanced construction procedures have been deployed allowing noticeable saving in construction cost normally involved with the implementation of this method (Luyun, 2010). Hanson and Nilsson (1986) reported from field study that areas with 1-5\% slope are the most feasible for subsurface dam installation, especially in high hydraulic conductivity environment. 
The effect of subsurface dams on saltwater intrusion has been investigated in Luyun et al. (2009) who provided an experimental study on the transient flushing rate of intruded saline water over underground dams of various heights. They concluded that a smaller wall height yielded faster flushing of saline water, as well as a smaller vertical extension of intruding saline plume along the shore. While the result presented by Luyun et al. (2009) are valuable for improving the understanding of flow dynamics imposed by subsurface dams, the previous investigations have so far only been limited to homogeneous soil formations, which is rarely found in real world problems. While heterogeneity is generally known to disturb the flow over many length scales (Abarca, 2006), prevalent heterogeneous formations such as aquifer stratification have been found to significantly modifies the flow path and rate near the coastal boundary ( $\mathrm{Lu}$ et al., 2013, Abdoulhalik and Ahmed, 2017). The presence of such heterogeneous layering is likely to strongly affect the performance of subsurface dams in preventing SWI.

To address this point, this paper aims to examine the use of subsurface dams as SWI intrusion control in heterogeneous aquifers. The effectiveness of subsurface dams was characterized by the ability 1) to restrict saltwater spillage and 2) to clean up the freshwater zone from residual saline water. This study provides for the first time an analysis of the spillage of saline water over the subsurface dam, which has never been captured in previous studies. More generally, this study is amongst the first attempts to provide insight on transience SWI in typical heterogeneous coastal aquifer settings in physical model.

The investigation was completed using a combination of laboratory experiments and numerical modelling simulations. The experiments were conducted in head-controlled groundwater system, where the freshwater level was varied to simulate groundwater fluctuations. Such aquifer systems deserve particular attention given their higher vulnerability to seawater intrusion compared to flux-controlled systems particularly when resulting from 
tidal fluctuations (Ataie-Ashtiani et al., 1999) and/or sea level rise (Ketabchi et al., 2016), and also because head-controlled aquifers represent more than $50 \%$ of the total world coastal aquifers (Michael et al., 2013). The numerical simulations were completed using the computer model SEAWAT for the validation of the experimental data.

\section{Materials and methods}

\subsection{Experimental method}

A laboratory flow tank of dimension $0.38 \mathrm{~m} \times 0.15 \mathrm{~m} \times 0.01 \mathrm{~m}$ was used to carry out the experiments (Fig 1). The tank was composed of three main parts, namely a central chamber to simulate the porous media and two side reservoirs at either side to impose head boundary conditions. The central chamber and the side reservoirs were separated by two fine mesh acrylic screens. Clear glass beads from Whitehouse Scientific ${ }^{\circledR}$ were siphoned into the central chamber under saturated conditions to limit the risks of air entrapment to simulate the porous medium. The packing of the beads was completed in even-sized layers and each layer was carefully tamped to provide uniform compaction.

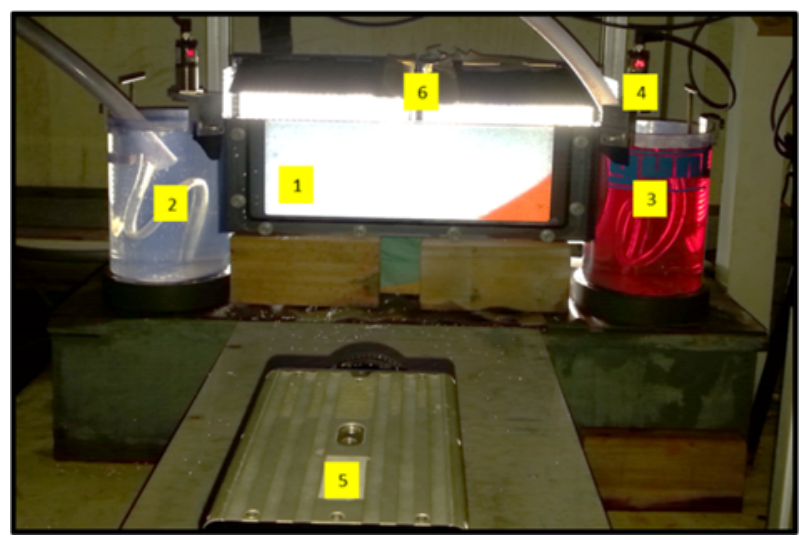

Figure 1 Photograph of the experimental set up; 1) porous media chamber; 2) freshwater reservoir; 3) saltwater reservoir; 4) ultrasonic sensors; 5) high speed camera; 6) LED lights

The left and right side reservoirs were used to supply freshwater and saltwater to the system, respectively. The saltwater solution was prepared prior to the experiments by dissolving commercial salt into freshwater at a concentration of $36.16 \mathrm{~g} / \mathrm{L}$. The saltwater solution was 
dyed with red food colour at a concentration of $0.15 \mathrm{~g} / \mathrm{L}$. The density of the saltwater solution was measured at $1025 \mathrm{~kg} / \mathrm{m}^{3}$ using a hydrometer (H-B Durac plain-form holycarbonate) and manually using mass/volume ratio.

Saltwater concentration was correlated with the intensity of the light transmitting through the main chamber using a calibration procedure, as described in details in Robinson et al. (2015, 2016). The light intensity-concentration conversion allowed the determination of key intrusion parameters under transient conditions. The images of the saltwater intrusion experiments were captured with a high speed camera with a resolution of $1280 \times 1024$ pixels and an 8-bit grayscale pixel depth. A MATLAB code was then used to obtain the light intensity-concentration parameters and then analyse all the experimental images to calculate the toe length of the saltwater wedge and provide maps of the solute concentration throughout the system.
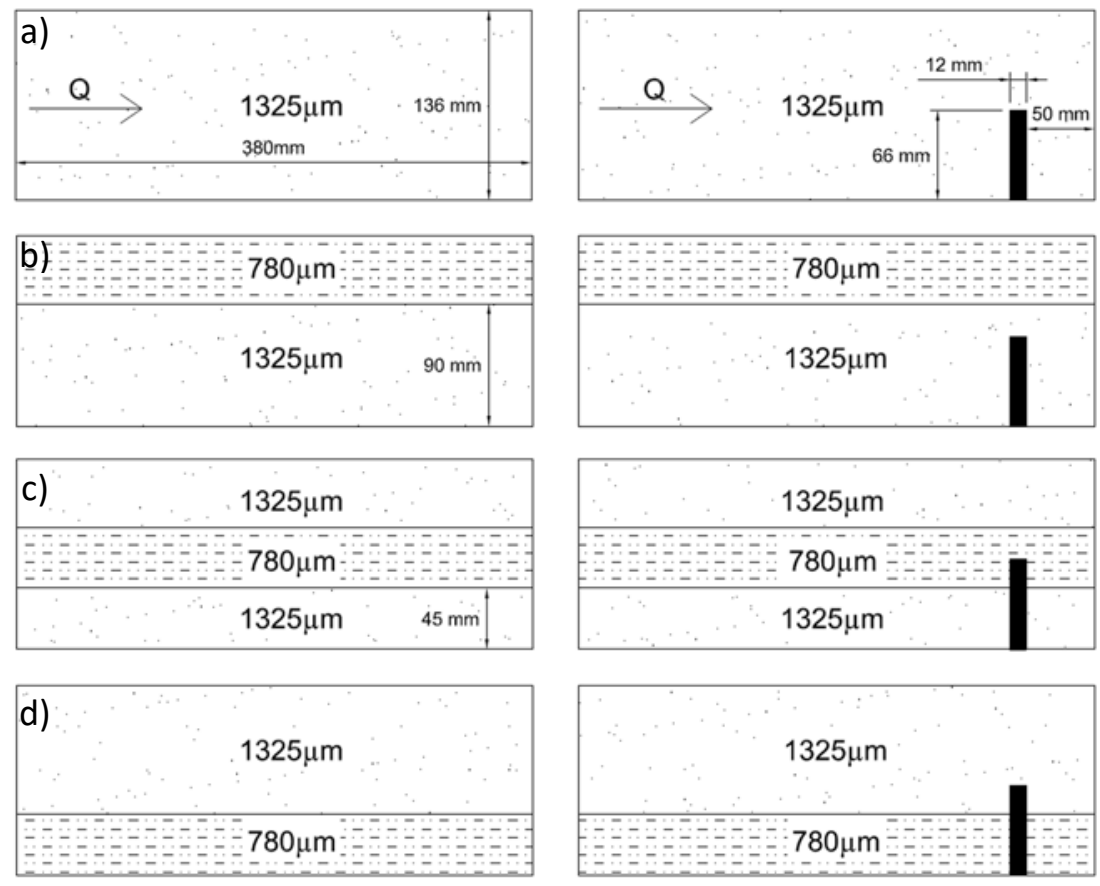

Figure 2 Schematic design of the investigated cases; the base cases (left) and after subsurface dam installation (right): a) case $H$; b) case $L H$; c) case HLH and d) case HL. 
In total, two sets of four experiments were completed (Fig 2), which included one set of base cases (without barrier) and another set incorporating a subsurface dam. The four base cases included a homogeneous case with relatively high permeability $(\mathrm{K})$, designated hereafter as case $\mathrm{H}$, and three different layered cases where a low $\mathrm{K}$ layer was set at three different locations: case Low K-High K (LH) presented a scenario where a low K layer was set in the top part of the aquifer; case High K-Low K-High K (HLH) referred to the case where a low K layer was located in the middle part of the aquifer; and case High K-Low K (HL) presented a scenario where a low $\mathrm{K}$ layer was set along the aquifer bottom. In all the cases, the thickness of the low K layer was about one third of the total saturated thickness of the homogeneous case $\mathrm{h}=136 \mathrm{~mm}$. The nominal diameter of the glass beads used to simulate the porous media and the low $\mathrm{K}$ layer was $1325 \mu \mathrm{m}$ and $780 \mu \mathrm{m}$, respectively. The average hydraulic conductivity of each type of beads was measured within the experimental flow tank using Darcy's law. The average hydraulic conductivity was estimated at $36 \mathrm{~cm} / \mathrm{min}$ and $108 \mathrm{~cm} / \mathrm{min}$ for the beads of size $780 \mu \mathrm{m}$ and $1325 \mu \mathrm{m}$, respectively.

The second set of experiments included a subsurface dam installed prior to siphoning of the beads into the tank. The subsurface dam was simulated using $12 \mathrm{~mm}$ wide PVC material covering the thickness of the tank. The dam was located at $50 \mathrm{~mm}$ from the seaside boundary, and has a height of $66 \mathrm{~mm}$ from the bottom boundary of the tank (about half of the saturated aquifer). The effect of the subsurface dam was examined within each of the four different aquifer settings, similar to the base cases.

In total, 48 experimental cases were carried out in this investigation. These includes 20 different experiments (4 physical experiments $\times 5$ different hydraulic gradients) for the base cases where the saltwater wedge was analysed in advancing and receding conditions; and 28 different experiments (4 physical experiments $\times 7$ different hydraulic gradients) for the 
subsurface dam cases, where the ability of subsurface dams to retain SWI and clean up aquifers from previously intruded saline water was assessed in the various aquifer settings.

\subsection{Experimental procedure}

The various hydraulic gradients were simulated by varying the freshwater level such that various head differences were successively imposed to the system. In all the investigated cases, the initial condition was set by forcing a head of $135.7 \mathrm{~mm}$ at the freshwater boundary to impose a first head difference $\mathrm{dh}=6 \mathrm{~mm}$ to the system, corresponding to a hydraulic gradient of 0.0158 . The dense saltwater solution was allowed to intrude into a fully freshwater aquifer, until the system reached the first steady state condition.

In the base cases, three head differences were applied thereafter, including $\mathrm{dh}=5.2 \mathrm{~mm}$, $\mathrm{dh}=$ $4.4 \mathrm{~mm}, \mathrm{dh}=3.6 \mathrm{~mm}$, corresponding to hydraulic gradients of $0.0137,0.0116$ and 0.0095 , respectively. The final head difference was eventually reset to the initial value $\mathrm{dh}=6 \mathrm{~mm}$ to allow the analysis of the seaward motion of the saltwater.

In the subsurface dam cases, two additional head differences were imposed to the system, specifically $\mathrm{dh}=2.8 \mathrm{~mm}$ and $\mathrm{dh}=2 \mathrm{~mm}$, corresponding to a hydraulic gradient of 0.0074 and 0.0053, respectively, before returning the head to $\mathrm{dh}=6 \mathrm{~mm}$. The application of these additional head difference was primarily to ensure the spillage of the saline water over the wall, which is primordial in this investigation. The highest and lowest head differences applied to the system $\mathrm{d}=6 \mathrm{~mm}$ and $\mathrm{dh}=2 \mathrm{~mm}$ corresponded to hydraulic gradient values of 0.0158 and 0.0053 , respectively. These gradient values are typical values used in similar laboratory studies (Abdoulhalik et al., 2017; Goswami and Clement, 2007; Chang and Clement, 2012) and within the range of values measured in some real coastal aquifers (Ferguson and Gleesson, 2012; Attanayake and Michael, 2007). 
The investigation of the effect of the subsurface dam on saltwater intrusion dynamics was subdivided into two mains phases, namely the advancing-wedge and the receding-wedge phases. The advancing-wedge phase includes the period prior to spillage where saltwater builds up in the seaward side of the wall, and the period post-spillage where saline water overflows the crest of the subsurface dam and penetrates into the freshwater zone. The receding-wedge phase relates to the removal of the residual saline water from the freshwater zone, after restoration of the initial freshwater head boundary condition.

The effectiveness of subsurface dams was characterized by two different criterions, depending on the phase analysed. The first criterion, used in the advancing-wedge phase, was the ability to restrict the SWI mechanism, which was identified differently depending on the location of the saltwater wedge toe on either side of the wall. When located on the seaward side of the wall (prior to spillage), the percentage reduction of the saltwater wedge length $\mathrm{R}$ was used, where $\mathrm{R}=\left(\mathrm{X}_{0}-\mathrm{X}_{\mathrm{d}}\right) / \mathrm{X}_{0}$, with $\mathrm{X}_{0}$ and $\mathrm{X}_{\mathrm{d}}$ are the intrusion length before and after the dam installation. When the toe was located on the landward side of the wall, the ability to restrict SWI was identified by $\mathrm{T}_{\text {spil }}$ and $\mathrm{T}_{\text {crit, }}$, corresponding respectively to the time taken for the saline water to start spilling over the wall and the time taken to reach the critical point $\mathrm{X}_{\text {crit, }}$, which was arbitrarily located at $90 \%$ of the total aquifer length from the seaside, at which the freshwater was considered completely contaminated. In the current system, the critical point

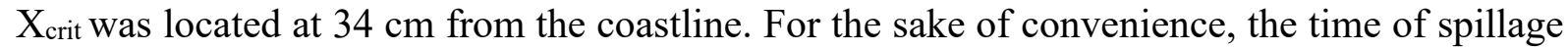
$\mathrm{T}_{\text {spil }}$ was defined as the time at which the overflowing of the saline water reaches the aquifer bottom in the landward side of the dam.

The second criterion used to characterise the performance of subsurface dams was the ability to completely flush out residual saline water in the seaward side of the wall during the receding-wedge phase. It was characterized by the time required for the freshwater zone to be completely cleaned up $\mathrm{T}_{\text {flush. }}$ 
The SEAWAT code (Guo et al., 2002) was adopted to validate the experimental results. The numerical model consisted in a rectangular domain of dimensions 38 x $14 \mathrm{~cm}$ with uniform size mesh of $0.2 \mathrm{~cm}$ representing the porous media chamber. The longitudinal dispersivity and the transverse dispersivity values were set to $0.1 \mathrm{~cm}$ and $0.05 \mathrm{~cm}$, respectively. The dispersivity and element dimensions provided numerical stability by satisfying the Peclet number criterion (Voss and Provost, 2010). A freshwater $(\mathrm{C}=0 \mathrm{~g} / \mathrm{L})$ hydrostatic boundary condition was forced on the left side boundary and a hydrostatic saltwater $(\mathrm{C}=36.16 \mathrm{~g} / \mathrm{L})$ boundary condition was applied on the right side boundary. The time step of the simulations was $0.5 \mathrm{~min}$ and $1 \mathrm{~min}$ for the base case and subsurface dam case simulations, respectively. A summary of the parameters involved in the numerical simulations is presented in table 1.

The SEAWAT code was used to simulate the base cases to assess the validity of the numerical model. At the initial condition, the model domain corresponded to an entirely fresh aquifer. The first stress period was used to set the first steady state condition, whereby the freshwater and saltwater boundary were set at $135.7 \mathrm{~mm}$ and $129.7 \mathrm{~mm}$, respectively, allowing penetration of saline water into a fully fresh model domain. In the next three stress periods, the freshwater head was dropped such that to impose head differences $\mathrm{dh}=5.2 \mathrm{~mm}$ and $4.4 \mathrm{~mm}, 3.6 \mathrm{~mm}$ to the system. The last stress period was dedicated for the retreat of the saltwater water wedge, following the rise of the head difference to its initial value $(\mathrm{dh}=6$ $\mathrm{mm})$.

The SEAWAT models were then used to perform numerical simulations incorporating the subsurface dam. The later was simulated by rendering the cells occupied by the wall as inactive. As noted above, two extra stress periods were added $(\mathrm{dh}=2.8 \mathrm{~mm}$ and $\mathrm{dh}=2 \mathrm{~mm})$ in the subsurface dam simulation to reproduce the spillage. The models were then used again 
to perform numerical simulations of the receding phase of the saline water in presence of the

232

233

subsurface dam. The initial condition corresponded to the final wedge for $\mathrm{dh}=2 \mathrm{~mm}$. A single stress period was thereafter used to initiate the saline water flushing process, following the rise of the inland freshwater head boundary to $135.7 \mathrm{~mm}$ to reset the initial $\mathrm{dh}=6 \mathrm{~mm}$.

Table 1 Summary of the numerical parameters

\begin{tabular}{|r|r|r|}
\hline Input Parameters & Value & Unit \\
\hline Domain length & 38 & $\mathrm{~cm}$ \\
\hline Domain height & 14 & $\mathrm{~cm}$ \\
\hline Element size & 0.2 & $\mathrm{~cm}$ \\
\hline Hydraulic Conductivity: & & \\
\hline$-780 \mu \mathrm{m}$ & 36 & $\mathrm{~cm} / \mathrm{min}$ \\
\hline Porosity & 108 & $\mathrm{~cm} / \mathrm{min}$ \\
\hline Longitudinal dispersivity & 0.38 & \\
\hline Transversal dispersivity & 0.1 & $\mathrm{~cm}$ \\
\hline Freshwater density & 0.05 & $\mathrm{~cm}$ \\
\hline Saltwater density & 1000 & $\mathrm{~kg} / \mathrm{m}^{3}$ \\
\hline Head difference, dh & 1025 & $\mathrm{~kg} / \mathrm{m}^{3}$ \\
\hline Stress period & $6,5.2,4.4,3.6,2.8$, & $\mathrm{mm}$ \\
\hline & 50 & $\mathrm{~min}$ \\
\hline
\end{tabular}

\section{Results and discussion}

\subsection{Base cases}
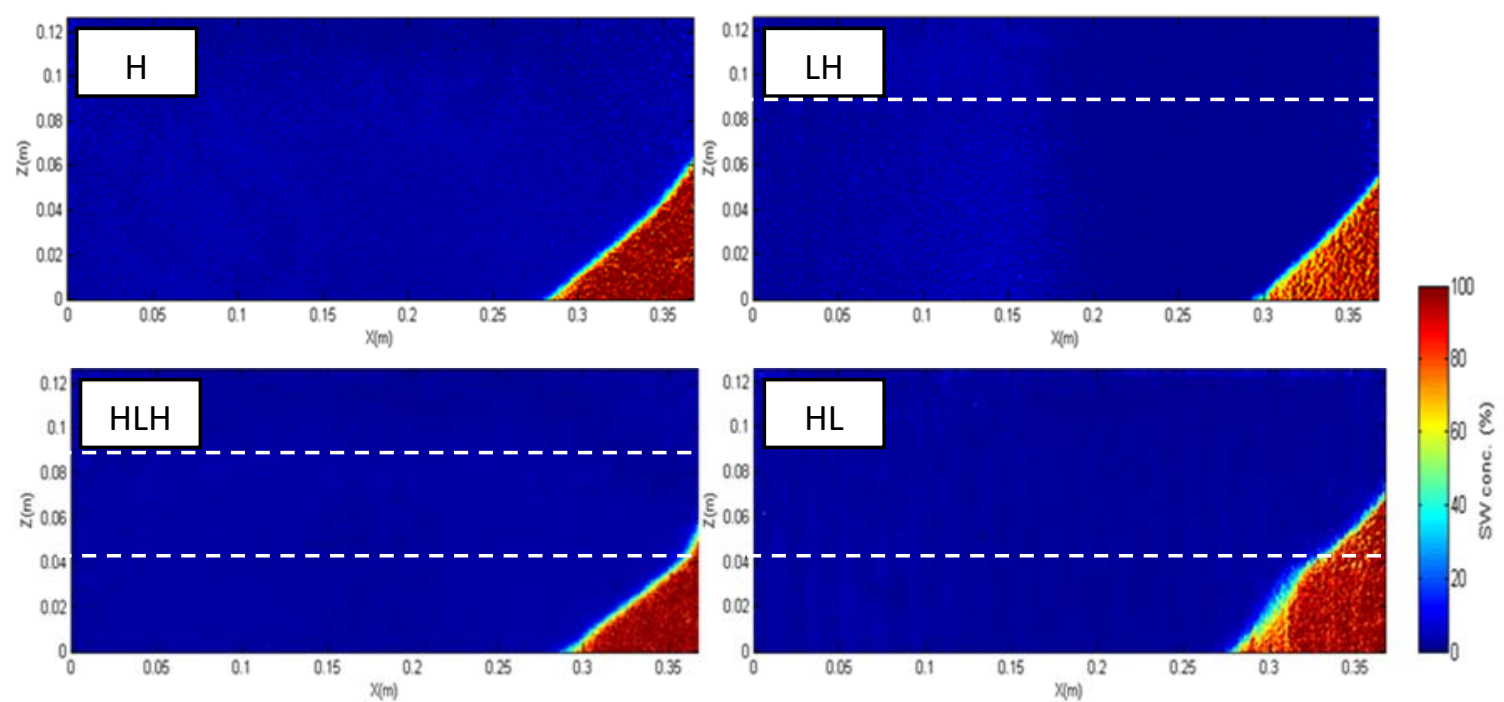

Figure 3 Concentration colour map of the experimental toe length at steady state after setting dh $=6 \mathbf{m m}(\mathrm{t}=0 \mathrm{~min})$ in the base case. The dashed lines represent the approximate location of the layer boundaries 
The assessment of the effectiveness of the subsurface dam and the understanding of the flow dynamics imposed by each layering pattern required first the analysis of saltwater intrusion dynamics in each aquifer setting, with no barrier. Fig 3 presents the concentration colour map of the base cases at the initial condition, i.e. after the application of the initial head difference $\mathrm{dh}=6 \mathrm{~mm}$. This first head change disrupted the equilibrium of the system and allowed the penetration of the saline water into the porous medium, forming an idealized wedge-like shape of the plume in homogeneous conditions, while slightly distorted in the heterogeneous cases HL and HLH, where the freshwater-saltwater interface crosses the boundary between two layers of contrasted permeability (Abdoulhalik and Ahmed, 2017). Such distortion of the wedge does not however occur in case LH, as the wedge penetrates "freely" into the high permeability zone, which accounts for two thirds of the aquifer height.

The further decrement of the head difference down to $\mathrm{dh}=3.6 \mathrm{~mm}$ induced a reduction in the freshwater flux transmitted to the system and thus allowing deeper inland encroachment of the saltwater wedge. The toe length data of all the investigated cases are presented in table 2 . The subsequent increase of the freshwater flow following resetting of the initial head difference to $\mathrm{dh}=6 \mathrm{~mm}$ forced the retreat of the saltwater toward the coastline boundary (Fig 4). The toe reached the same position as in the initial condition in all cases, which indicates that no hysteresis occurred in the system.

Table 2 Experimental toe length values $(\mathrm{cm})$

\begin{tabular}{|c|c|c|c|c|}
\hline Head difference & Case H & Case LH & Case HLH & Case HL \\
\hline $\mathbf{d h}=\mathbf{6} \mathbf{~ m m}$ & 8.4 & 6.6 & 7.4 & 8.6 \\
\hline $\mathbf{d h}=\mathbf{5 . 2} \mathbf{~ m m}$ & 11.7 & 9.2 & 11.2 & 11.1 \\
\hline $\mathbf{d h}=\mathbf{4 . 4} \mathbf{~ m m}$ & 17.2 & 13.5 & 16.3 & 16.7 \\
\hline $\mathbf{d h}=\mathbf{3 . 6} \mathbf{~ m m}$ & 25.5 & 20.8 & 25.0 & 22.9 \\
\hline
\end{tabular}




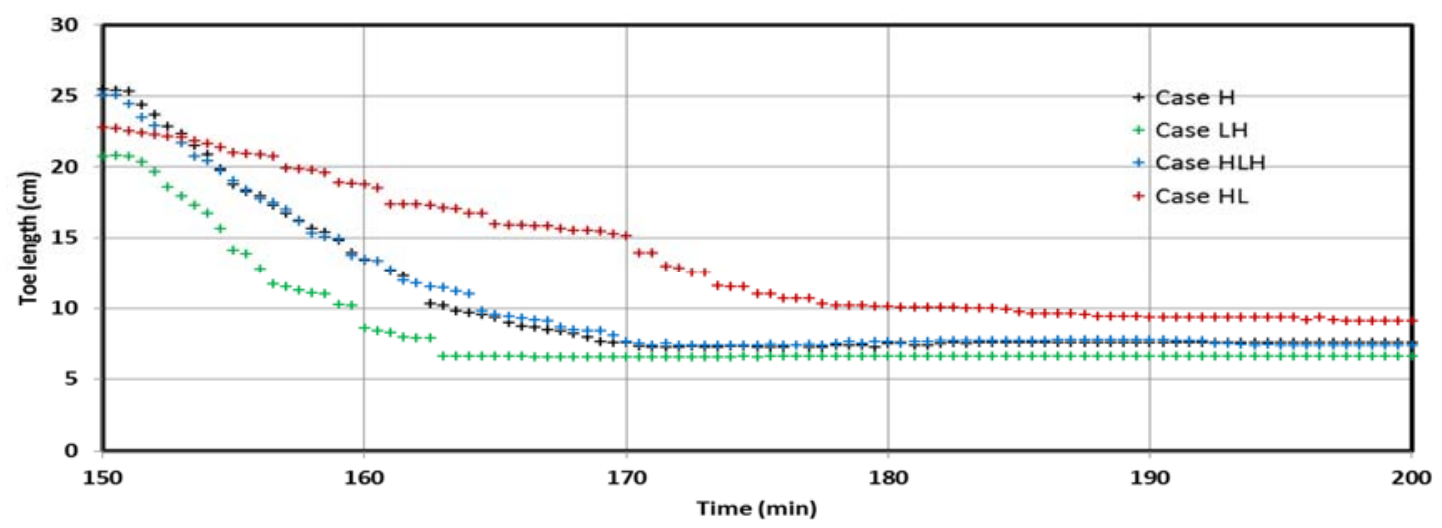

273

274

275

276

277

278

279

280

281

282

283

284

285

286

Figure 4 Experimental transient toe length data during saltwater retreat

The data show that the shortest saltwater intrusion toe length was exhibited in case LH for all the inland heads applied. In such configuration, the existence of the low $\mathrm{K}$ on the top of the aquifer drives part of the freshwater flow into the bottom layer that has greater hydraulic conductivity, i.e. directly facing the saltwater wedge, thereby obstructing its inland penetration. In other words, the freshwater flow is increased in the lower part of the aquifer, which leads to a greater repulsion of the saltwater wedge back towards the coast. This result is in agreement with the steady state analysis presented by Strack et al. (2016), where similar configuration was examined. The transient data provided in Fig 4 shows that the receding toe motion in this setting is noticeably faster compared to the homogeneous scenario, which indicate higher freshwater flow velocity promoting faster repulsion of the saline wedge.

The toe length was also shorter in case HLH relative to the homogeneous case, albeit the difference is less obvious here. The low $\mathrm{K}$ layer in the middle portion of the aquifer is expected to force the freshwater to flow on the top and bottom parts of the aquifer. While the freshwater flowing in the top high $\mathrm{K}$ layer exits the system without substantial contribution in the saltwater wedge repulsion, the flow in the bottom layer of high $\mathrm{K}$ has greater impact to push the wedge in the seaward direction resulting in shorter wedge compared to the homogeneous scenario. This observation is analogous to that reported in Abdoulhalik and 
292 Ahmed (2017) and $\mathrm{Lu}$ et al. (2013) where saltwater intrusion mechanism in such typical 293 heterogeneous aquifer setting was also analysed.

294 The longer toe length values recorded in case HL compared to those observed in case LH are 295 consistent with Strack et al. (2015) where the saltwater intrusion length in their dual-layered 296 aquifer with underlying low K layer was up to twice longer than the opposite scenario. The 297 transient data shows that the toe motion exhibited in this setting is considerably slower 298 compared to the other cases. While the saltwater intrusion process is mainly controlled by the 299 freshwater flow transmitted through the system (Chang and Clement, 2012), the freshwater 300 flow transiting in the lower part of the aquifer is considerably slowed through the underlying 301 low K layer, which resulted in inhibiting the effective seaward repulsion of the saline water. 302 The subsequent increase of the flow velocity in the upper part of the aquifer is little involved 303 in the repulsion effort, but rather directly exits at the outlet. 

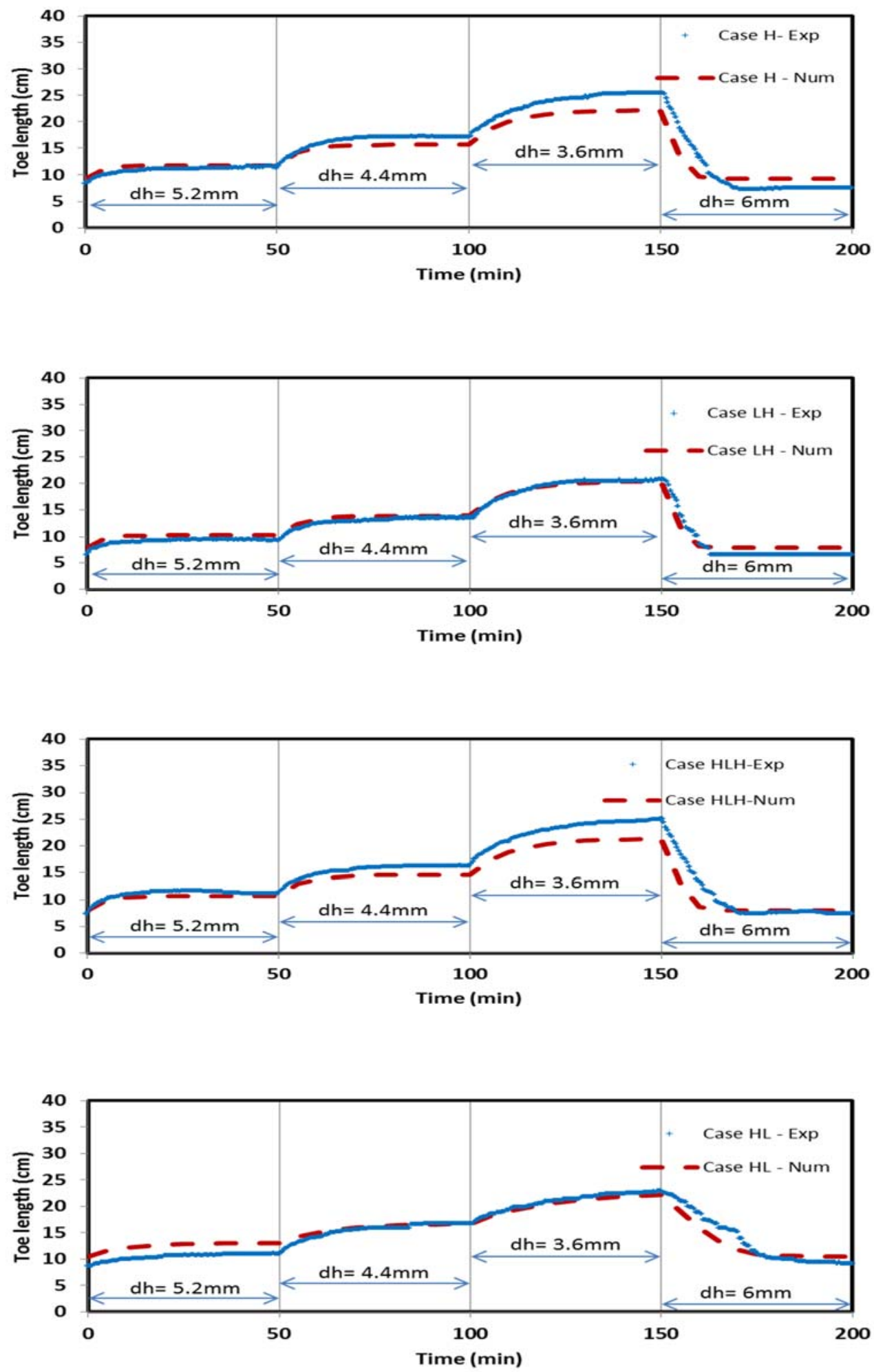

308 Figure 5 Comparison of the transient experimental and numerical toe length results of the base cases

310 The comparison between the experimental and numerical toe length results of the base cases

311 are shown in Fig 5. The transient experimental toe length data were very well predicted by the 
SEAWAT model in all the cases. The largest toe length was however observed in case HL,

while compared to the other numerical cases. This may be because the experimental case HL

314 has not reached the complete steady-state condition, as the penetration of the wedge was very

315 slow through the underlying low K layer. The numerical results nonetheless show that the

316 minimum intrusion length was occurs in case LH, in agreement with the experimental

317 observations. The resulting models were then used to simulate the subsequent subsurface dam experiments for each respective aquifer setting, as shown below.

\section{Advancing-wedge phase}
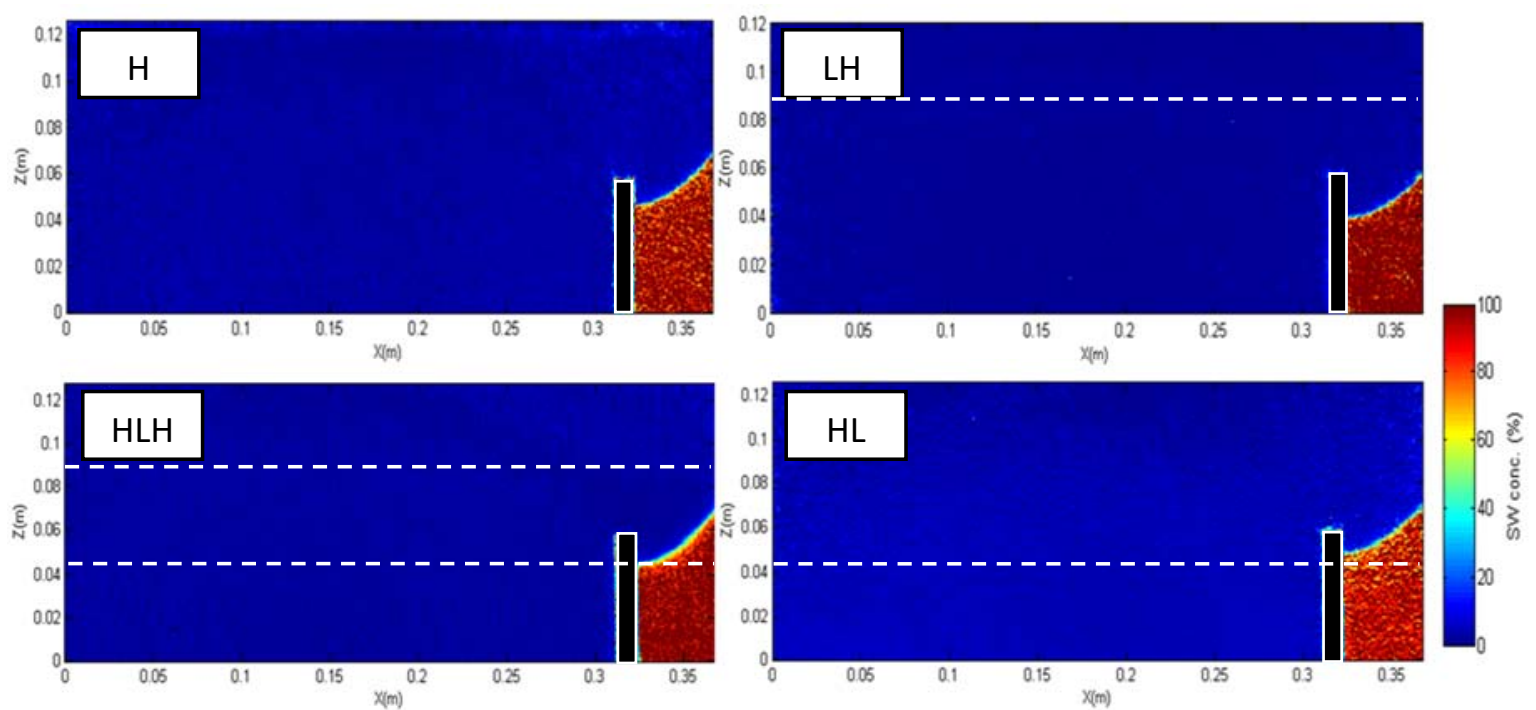

Figure 6 Concentration colour map of the experimental saltwater wedge at the steady state in the subsurface dam case after setting $\mathrm{dh}=6 \mathrm{~mm}$.

Table 3 Percentage reduction $R$ of saltwater intrusion length achieved by the subsurface dam

\begin{tabular}{|c|c|c|c|c|}
\hline Head difference dh $\mathbf{( m m})$ & Case H & Case LH & Case HLH & Case HL \\
\hline $\mathbf{d h}=\mathbf{6} \mathbf{~ m m}$ & $41 \%$ & $25 \%$ & $33 \%$ & $42 \%$ \\
\hline $\mathbf{d h}=\mathbf{5 . 2} \mathbf{~ m m}$ & $57 \%$ & $46 \%$ & $55 \%$ & $55 \%$ \\
\hline $\mathbf{d h}=\mathbf{4 . 4} \mathbf{~ m m}$ & $71 \%$ & $63 \%$ & $69 \%$ & $70 \%$ \\
\hline $\mathbf{d h}=\mathbf{3 . 6} \mathbf{~ m m}$ & $80 \%$ & $76 \%$ & $80 \%$ & $78 \%$ \\
\hline
\end{tabular}

Fig 6 shows the concentration colour maps of the subsurface dam experiments at the initial conditions, i.e after applying $\mathrm{dh}=6 \mathrm{~mm}$. In all the investigated cases, the subsurface dam was able to retain the intrusion of saline water for all the head differences applied to the base 
cases, i.e. up to $\mathrm{dh}=3.6 \mathrm{~mm}$, which means that the subsurface dam could withstand the saltwater intrusion process associated with a decrement of the gradient from 0.0158 down to 0.0095. This was expected because the height of the saltwater wedge in the base cases at the location of the wall is slightly smaller than the height of the subsurface dam (Luyun et al., 2009; Abdoulhalik et al., 2017). The values of the percentage reduction of intrusion length $\mathrm{R}$ achieved by the subsurface dam are presented in table 3. The lowest values of reduction are recorded in case LH for all the head differences tested. This is because the difference $\mathrm{X}_{0}-\mathrm{X}_{\mathrm{d}}$ is the smallest in case $\mathrm{LH}$, given that it exhibited the smallest toe length values prior to wall installation, while $\mathrm{X}_{\mathrm{d}}$ is limited by the location of the subsurface dam in all the cases.

In order to observe the spillage of saline water over the wall, the head difference was thereafter gradually decreased by maintaining a step head decrement of $0.8 \mathrm{~mm}$. The initial condition of this experiment $(\mathrm{t}=0 \mathrm{~min})$ corresponded to the steady state saltwater wedge under $\mathrm{dh}=3.6 \mathrm{~mm}$. The spillage process was first observed following the application of $\mathrm{dh}=$ $2.8 \mathrm{~mm}$ in case HL (Fig 7), while an additional inland head drop ( $\mathrm{dh}=2 \mathrm{~mm}$ ) was needed in cases H, LH and HLH (Fig 8). In other words, the spillage of saline water occurred following the application of a hydraulic gradient 0.0074 in case HL, and 0.0053 in the other cases.

In case HL, the spillage occurred 12 min following the application of $\mathrm{dh}=2.8 \mathrm{~mm}$, and it took nearly $100 \mathrm{~min}$ for the saltwater length to extend up to $21.6 \mathrm{~cm}$ from the sea boundary (or $15.4 \mathrm{~cm}$ from the left edge of the wall) where it became quasi steady. A significant widening of the transition zone occurred during the spillage in all cases, due to the excessive dispersion and diffusion occurring along the freshwater-saltwater interface. The further decrement of the head difference to $\mathrm{dh}=2 \mathrm{~mm}$ prompted the saline water to extend up to the critical point $\mathrm{X}_{\text {crit }}$ within $29 \mathrm{~min}$. This observation shows that the ability of the subsurface dam to retain the saltwater intrusion process was significantly weakened in presence of the low permeability at the bottom part of the aquifer. 

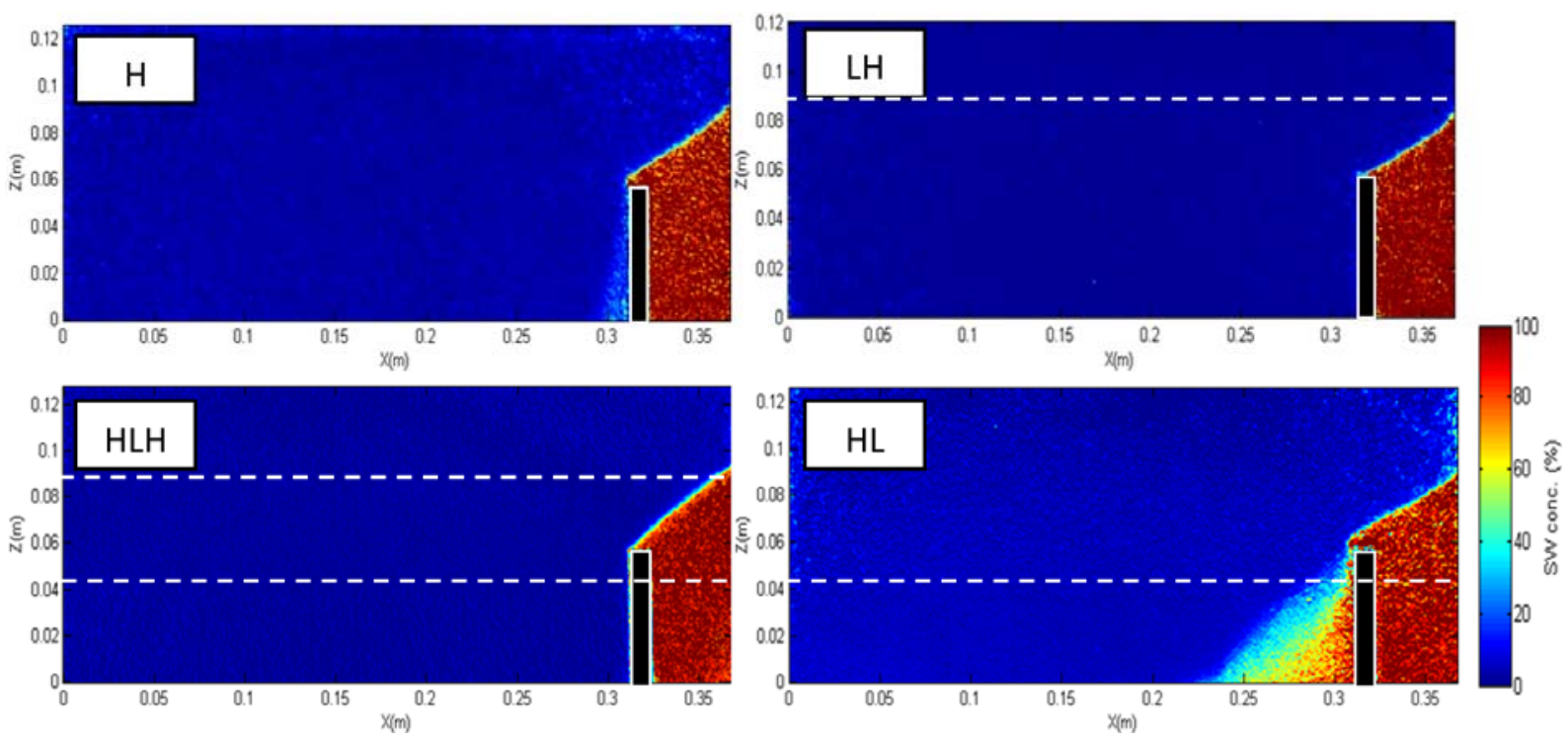

354

Figure 7 Concentration colour map of the experimental saltwater wedge at steady state in the subsurface dam case at $=\mathbf{5 0}$ min after decreasing the head difference from $\mathbf{d h}=\mathbf{3 . 6} \mathbf{m m}$ to $\mathbf{d h}=$ $2.8 \mathrm{~mm}$

After decreasing the head difference from $\mathrm{dh}=2.8 \mathrm{~mm}$ to $\mathrm{dh}=2 \mathrm{~mm}$, Fig 8 shows that, at first glance, the inland progression of the saltwater wedge was inhibited in presence of a low $\mathrm{K}$ layer in the middle (case HLH) and top part of the aquifer (LH). The spillage process also exhibited different pattern depending on the layer arrangement. In case $\mathrm{LH}$, the saline water almost dripped into the landward side of the wall with an interface exhibiting a slightly curved shape compared to the homogeneous case. In cases LH and HLH, the transition zone was noticeably wider than the homogeneous case with the case HLH exhibiting greatest transition zone and slowest spillage. Nevertheless, the spillage caused substantial widening of the transition zone in all cases even in case $\mathrm{H}$, especially near the location of the dam, caused by the excessive dispersion along the interface. It is very interesting to note in case HLH the substantial reduction of the salt concentration of the residual saline water in the landward side of the wall, probably caused by much stronger dispersion in the lower portion of the aquifer, where the flow is increased due to the middle low $\mathrm{K}$ layer. 

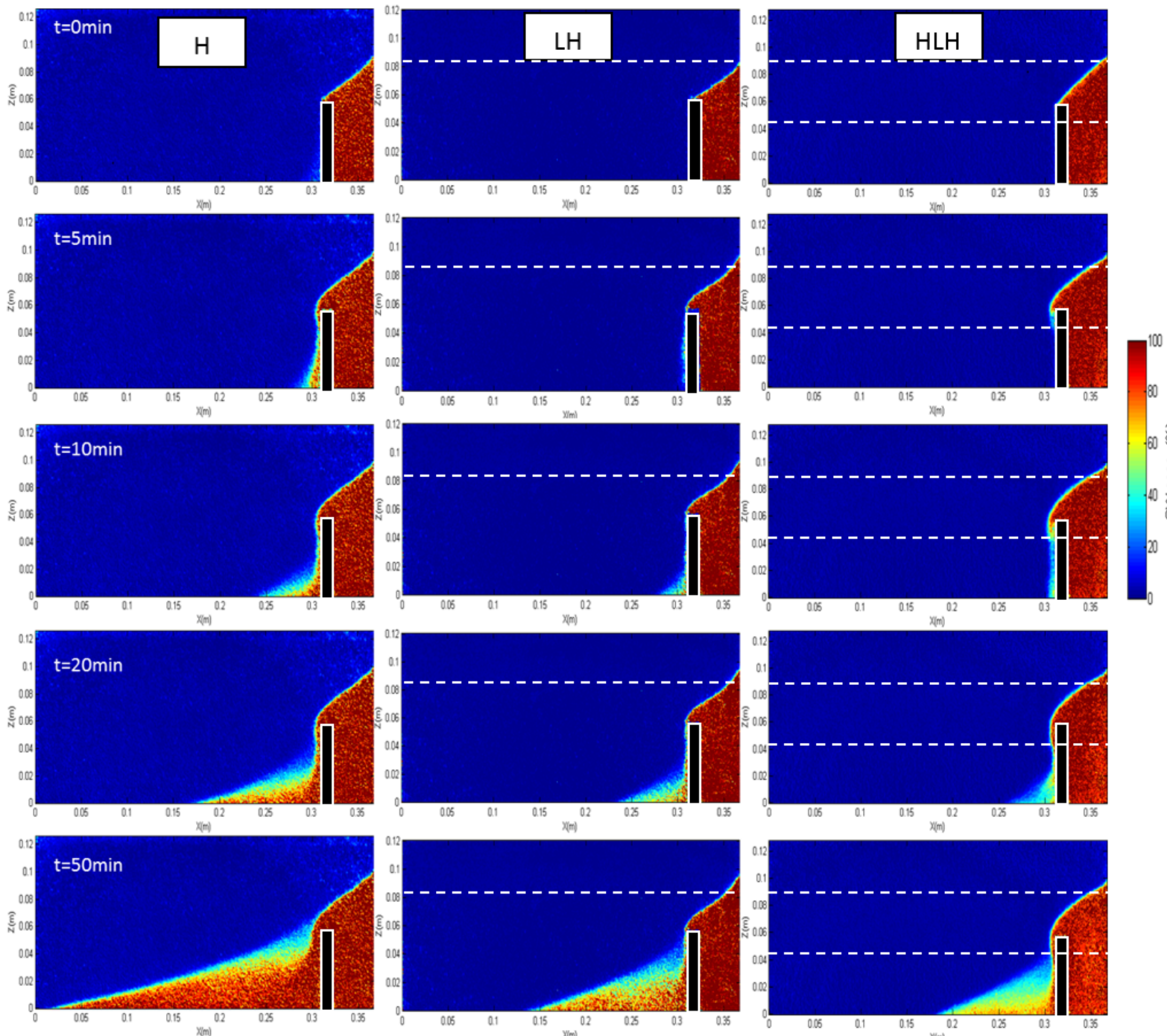

Figure 8 Transient experimental advancing-wedge phase in the subsurface dam case after decreasing the head difference from $\mathrm{dh}=\mathbf{2 . 8} \mathrm{mm}$ to $\mathrm{dh}=\mathbf{2} \mathrm{mm}$

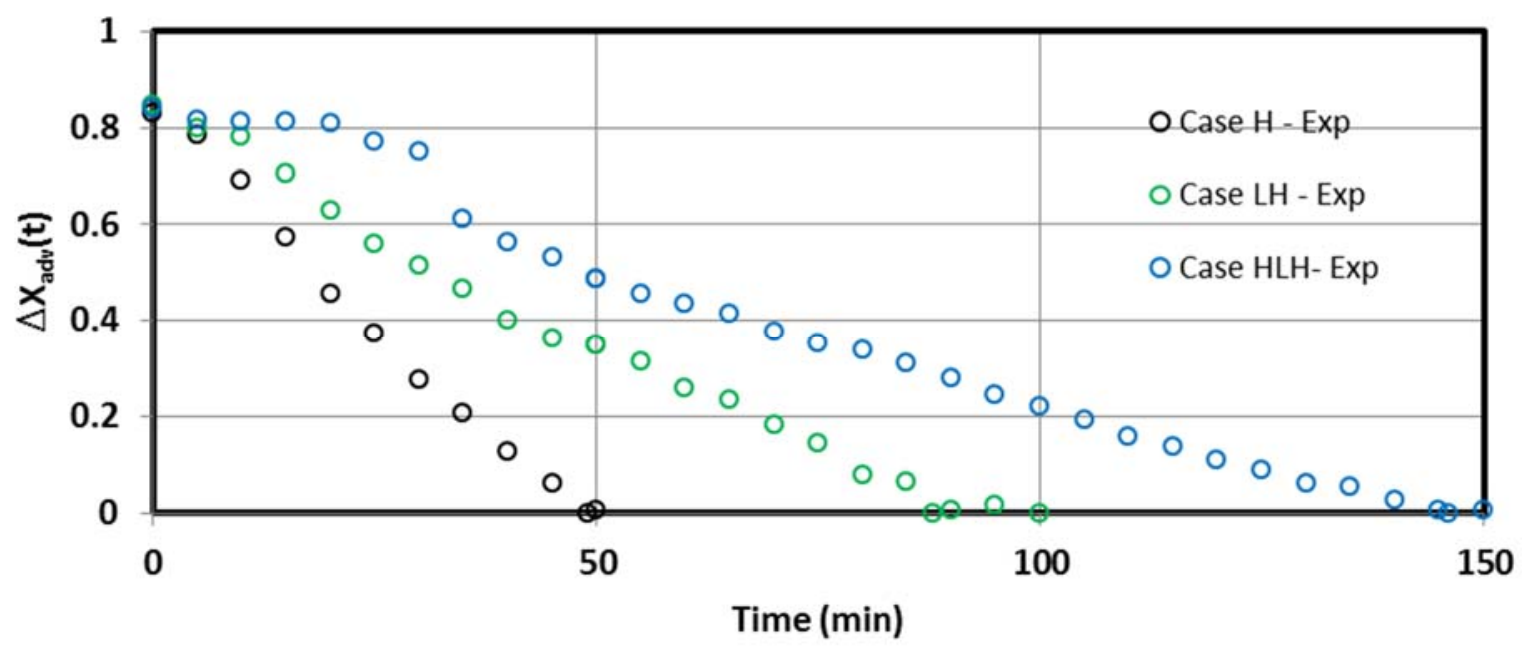

Figure 9 Transient experimental toe intruding rates following the saline water spillage in case $\mathrm{H}$, 
The rate of inland extension of the saline water was quantified in each case in order to assess the difference in time taken to reach the critical point $\mathrm{X}_{\text {crit, }}$ following the head decrement from $\mathrm{dh}=2.8 \mathrm{~mm}$ to $\mathrm{dh}=2 \mathrm{~mm}$. The parameter $\Delta \mathrm{X}_{\mathrm{adv}}(\mathrm{t})$ is introduced to characterise the distance to be travelled by the toe before reaching $X_{\text {crit }}$, such that $\Delta X_{\text {adv }}(t)=a b s\left[X(t)-X_{\text {crit }}\right] / X_{\text {crit }}$; where $\mathrm{X}(\mathrm{t})$ is the toe length at time $\mathrm{t}$. We considered that the critical point $\mathrm{T}_{\text {crit }}$ was reached when $\Delta \mathrm{X}_{\mathrm{adv}}(\mathrm{t})$ becomes smaller than $1 \%$. The curves of $\Delta \mathrm{X}_{\mathrm{adv}}(\mathrm{t})$ are shown in Fig 9 and the recorded $\mathrm{T}_{\text {spil }}$ and $\mathrm{T}_{\text {crit }}$ values are presented in table 4 . Note that in case HL the saline water has already intruded deeper into the freshwater zone prior to applying $\mathrm{dh}=2 \mathrm{~mm}$; it was therefore not deemed necessary to include this case in this analysis.

The data show that the inland extension of the saline water was considerably lower in cases LH and HLH compared to the homogeneous scenario (Fig 9). This means that the rate of saline water spillage was much slower in presence of the low permeability layer in the central and top part of the aquifer. This slower intruding rate is clearly manifested by the milder slope observed in case LH and HLH, while a much steeper slope is exhibited in case H, indicating faster intrusion. This is further confirmed by the delayed starting times of spillage $T_{\text {spil }}$ observed in the heterogeneous cases compared to the homogeneous setting, as well as the recorded values of $\mathrm{T}_{\text {crit }}$, which are nearly twice in case $\mathrm{LH}$ and three times greater in HLH, compared to the homogeneous scenario.

Table 4 Experimental time required for the saline water to spill $\left(T_{\text {spil }}\right)$ and to reach the critical point $T_{\text {crit }}$ in case $\mathrm{H}, \mathrm{LH}$ and HLH following the head decrement from $\mathrm{dh}=2.8 \mathrm{~mm}$ to $\mathrm{dh}=2$ mm.

\begin{tabular}{|c|c|c|}
\hline Cases & $\mathbf{T}_{\text {spil }}$ & $\mathbf{T}_{\text {crit }}$ \\
\hline Case H & $4 \mathrm{~min}$ & $49 \mathrm{~min}$ \\
\hline Case LH & $7 \mathrm{~min}$ & $88 \mathrm{~min}$ \\
\hline Case HLH & $10 \mathrm{~min}$ & $146 \mathrm{~min}$ \\
\hline
\end{tabular}


400

401

402

403

404

405

406

407

408

409

410

411

412

413

414

415

416

417

418

2

Comparison between the numerical data and the experimental results for the advancing-wedge phase is shown in Fig 10. The simulation results yielded very good agreement with the experimental data in all cases. The numerical model confirms the ability of the dam to retain saline water for the all the various inland head previously applied to the bases cases, yielding a reduction of $77 \%, 76 \%, 77 \%$ and $78 \%$ in case $\mathrm{H}, \mathrm{LH}, \mathrm{HLH}$ and $\mathrm{HL}$ respectively. The model predicted the spillage of saltwater following the application of $\mathrm{dh}=2.8 \mathrm{~mm}$ in case HL, while no spilling occurred in the other cases until $\mathrm{dh}=2 \mathrm{~mm}$ was applied to the system, in agreement with the experimental observations. The curves show that both the starting time of the spillage and the intruding rate of the saline water are consistent with the experimental data in all cases. The results demonstrate that the ability of subsurface dams to control saline water intrusion mechanism is strongly affected by the existence of stratified layers and the stratification pattern. 


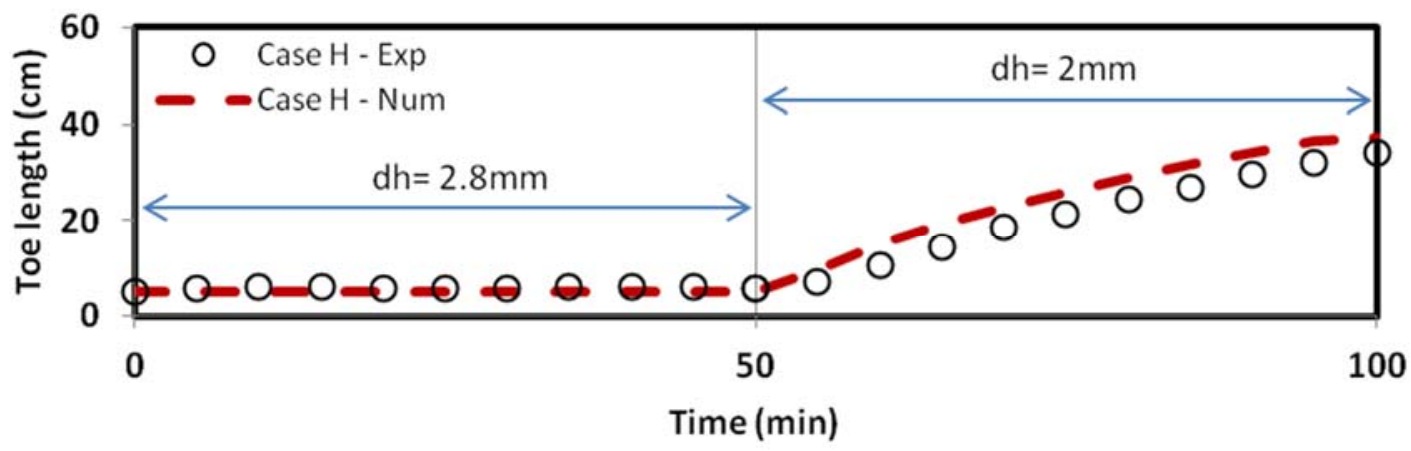

419

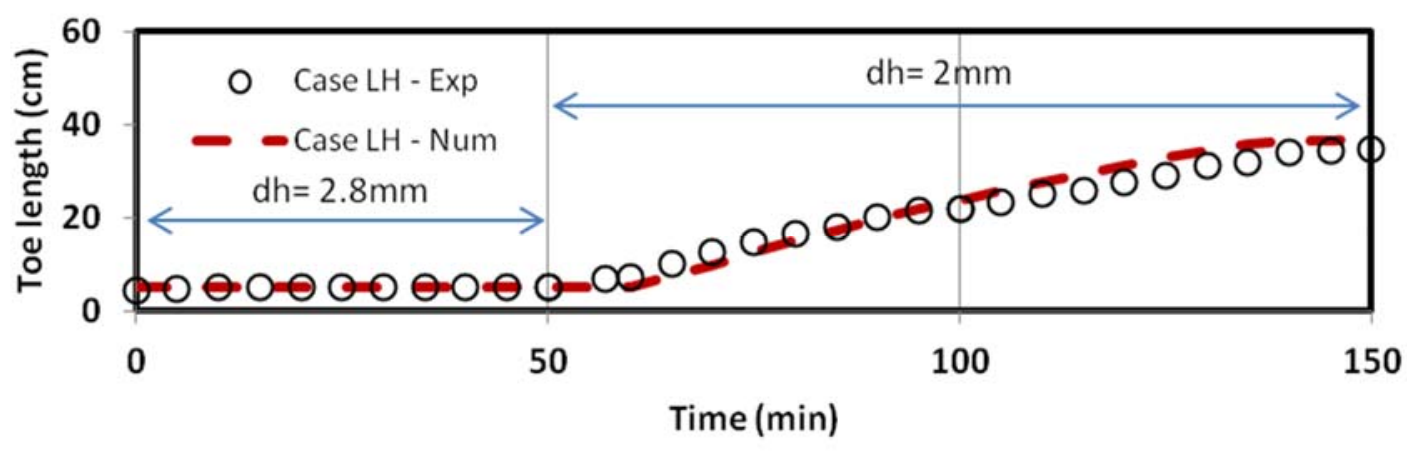

420

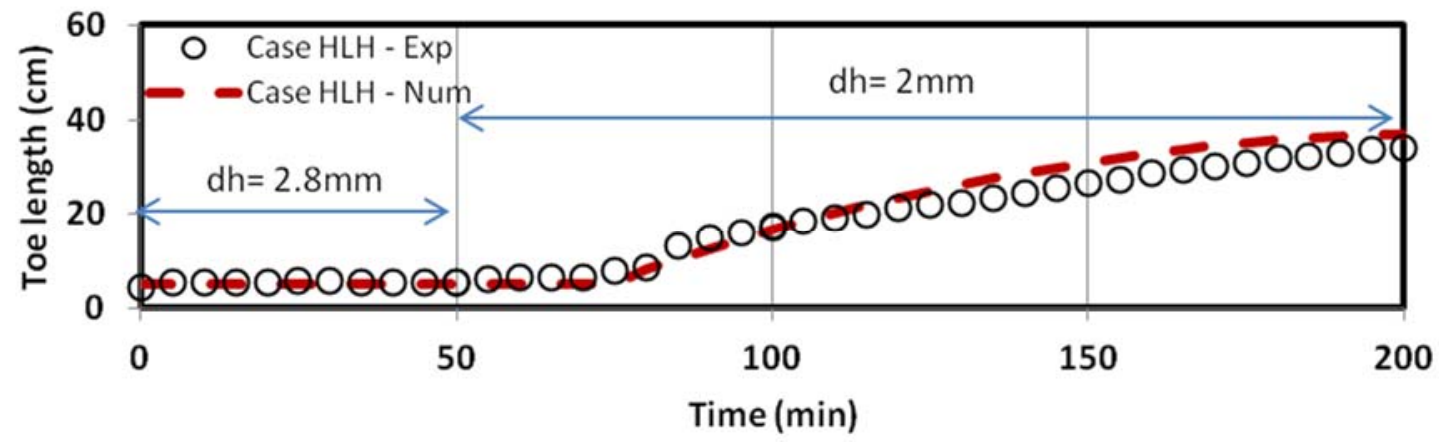

421

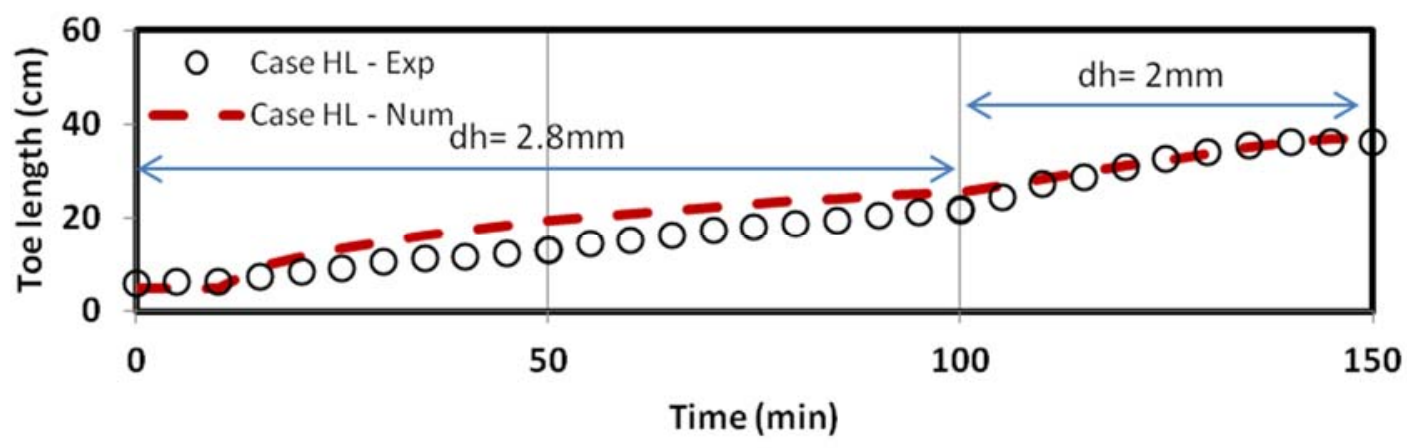

423 Figure 10 Comparison of the transient experimental and numerical toe length results of the 424 subsurface dam cases during the intruding phase 
An analysis of the flow velocity vectors was completed to gain an insight on the impact of each layering pattern on the flow dynamics before the spillage of saline water over the subsurface dam (Fig 11). The model-predicted inflow rate was also recorded in each aquifer setting, as shown in table 5. As expected, the inflow rate was maximal in the homogeneous case and the flow velocity vectors exhibited relatively similar magnitude throughout the system. Obviously, the magnitude of the vectors was very low at the bottom right corner, i.e within the location of the saltwater wedge, and very high at the top right corner of the model domain, i.e. where the freshwater exits the system. The magnitude of the flow velocity vectors was also substantially high at the crest of the subsurface dam, indicating that the freshwater discharge velocity increases over the wall, thereby exerting a downward pressure on the saline plume on the seaward side of the wall, which is in agreement with Luyun et al. (2009).

In the layered cases, the results show that there are basically three main processes that influence the saltwater intrusion mechanism which depend essentially on the location of the low permeability zone in the system. The first process, occurring in case LH, is the downwards channelling of the freshwater flow between the crest of the wall and the interlayer boundary. Hence, the freshwater flow increases in the reduced cross section, which result in more "pushing" effects exerted on the saltwater plume, thereby leading to a more effective resistance to the buoyancy forces which drive the intrusion of saline water. This is clearly shown in Fig 11, where the flow velocity vectors of highest magnitude were all located between the crest and the layer boundary, resulting in a visibly smaller saline plume and a rather curvier interface, in agreement with the experimental observations (Fig 6). In other words, the ability of the subsurface dam to resist SWI mechanism increased compared to the homogeneous case, despite the recorded inflow rate was decreased by $32 \%$ in this setting relative to the homogeneous scenario. It is also interesting to note that the inflow rate was smaller than in case HL, which suggests that the flow magnitude at the crest of the wall has 

inflow rate.

452
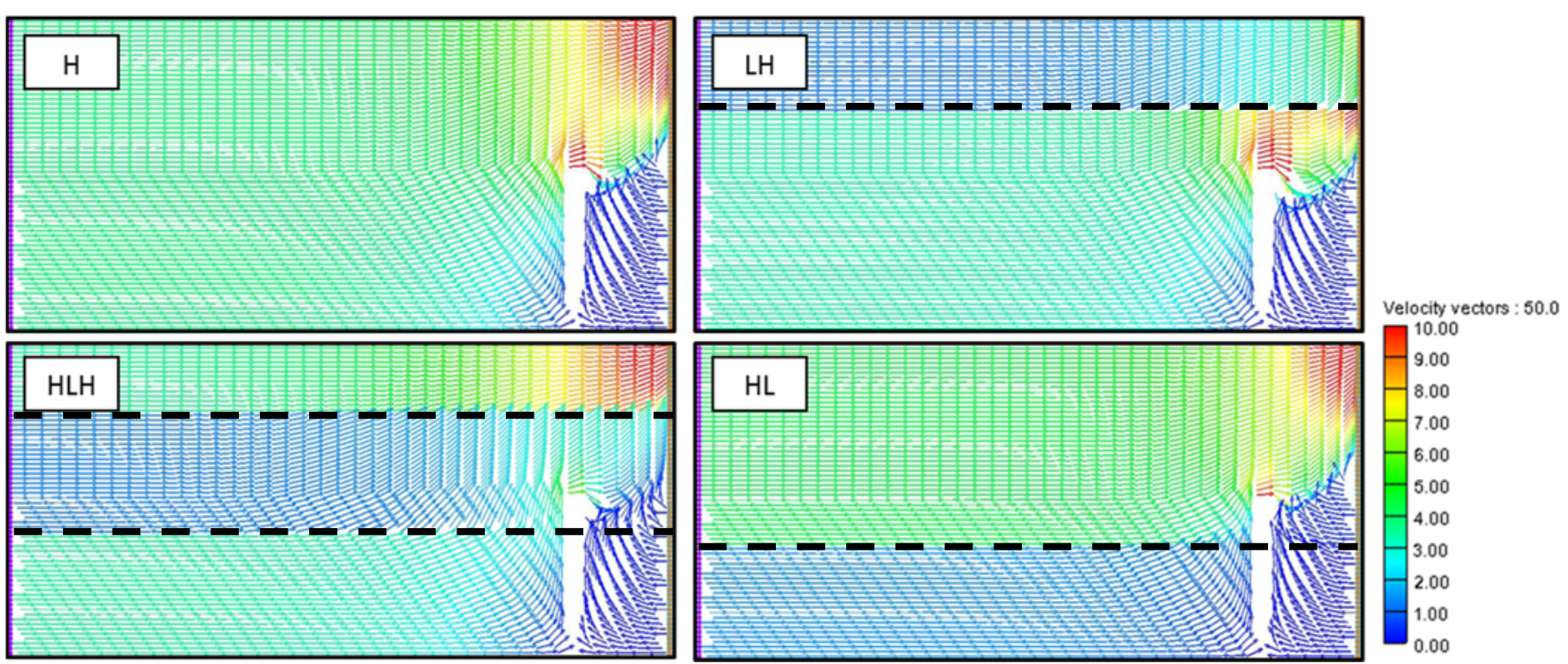

Figure 11 Maps of the flow velocity field at steady state after application of $\mathrm{dh}=6 \mathrm{~mm}$. The velocity vectors are in $\mathrm{cm} / \mathrm{min}$.

Table 5 Model-predicted inflow rates $Q_{\text {in }}$ at steady state $(\mathrm{dh}=6 \mathrm{~mm})$

\begin{tabular}{|c|c|c|c|c|}
\hline Cases & Case $\mathbf{H}$ & Case LH & Case HLH & Case HL \\
\hline $\mathbf{Q}_{\text {in }}\left(\mathbf{c m}^{\mathbf{3}} / \mathbf{m i n}\right)$ & 15.9 & 10.8 & 12.3 & 13.6 \\
\hline
\end{tabular}

The second process, taking place in case HLH, is the weakening of the density contrast effects induced by intense mixing occurring as the seaward saline plume is forced to rise through low permeability material. The considerably lower solute concentration of the intruded saline water observed in case HLH at $\mathrm{t}=50 \mathrm{~min}$ tends to support this explanation (Fig 8). Hence, this process directly reduces the buoyancy forces and therefore helps the subsurface dam to withstand the SWI mechanism, despite the magnitude of the flow velocity at the crest as well as the inflow rate were both smaller than the homogeneous case. 
The third process, occurring in case HL, is the subsequent slowdown of the freshwater flow in the lower part of the system leading to the lowering of the freshwater flow at the crest of the wall. This is clearly observable in Fig 11, where the red zone at the crest of the wall is much smaller than the homogeneous case. In other words, the flow at the crest exerts lesser resistance to the buoyancy forces driving the intrusion compared to the homogeneous case. This means that in such condition, the building up of the saline plume on the seaward side of the wall is facilitated. This process therefore causes the weakening of the ability of the subsurface dam to restrict the saline water intrusion mechanism, and induce easier saltwater spillage compared to a homogeneous scenario, following even lesser drop of the inland head boundary.

\section{Receding-wedge phase}

The receding-wedge phase was initiated by instantaneously raising the freshwater level such that to increase the head difference from $\mathrm{dh}=2 \mathrm{~mm}$ to the initial value $\mathrm{dh}=6 \mathrm{~mm}$. This subsequently caused a sharp increase of the freshwater flow throughout the system that abruptly repulsed the saline water towards the seaside (Fig 12). The receding process was associated with a significant widening of the transition-zone due to the sharp increase of the freshwater flow that transported saline flux along the freshwater-saltwater interface, especially in case HLH, where the lifted saline water passed through the lower permeability media. The removal of the saline water was not completed within $50 \mathrm{~min}$ in none of the investigated cases. Rather, the residual saltwater became relatively steady towards the end of the test period, forming a smaller residual wedge on the landward side of the wall. At $t=50$ $\mathrm{min}$, the lengths of the residual wedge measured from landward edge of the wall were $5.4 \mathrm{~cm}$, $5.2 \mathrm{~cm}, 5.1 \mathrm{~cm}$ and $7 \mathrm{~cm}$ in case $\mathrm{H}, \mathrm{LH}, \mathrm{HLH}$ and HL, respectively. 

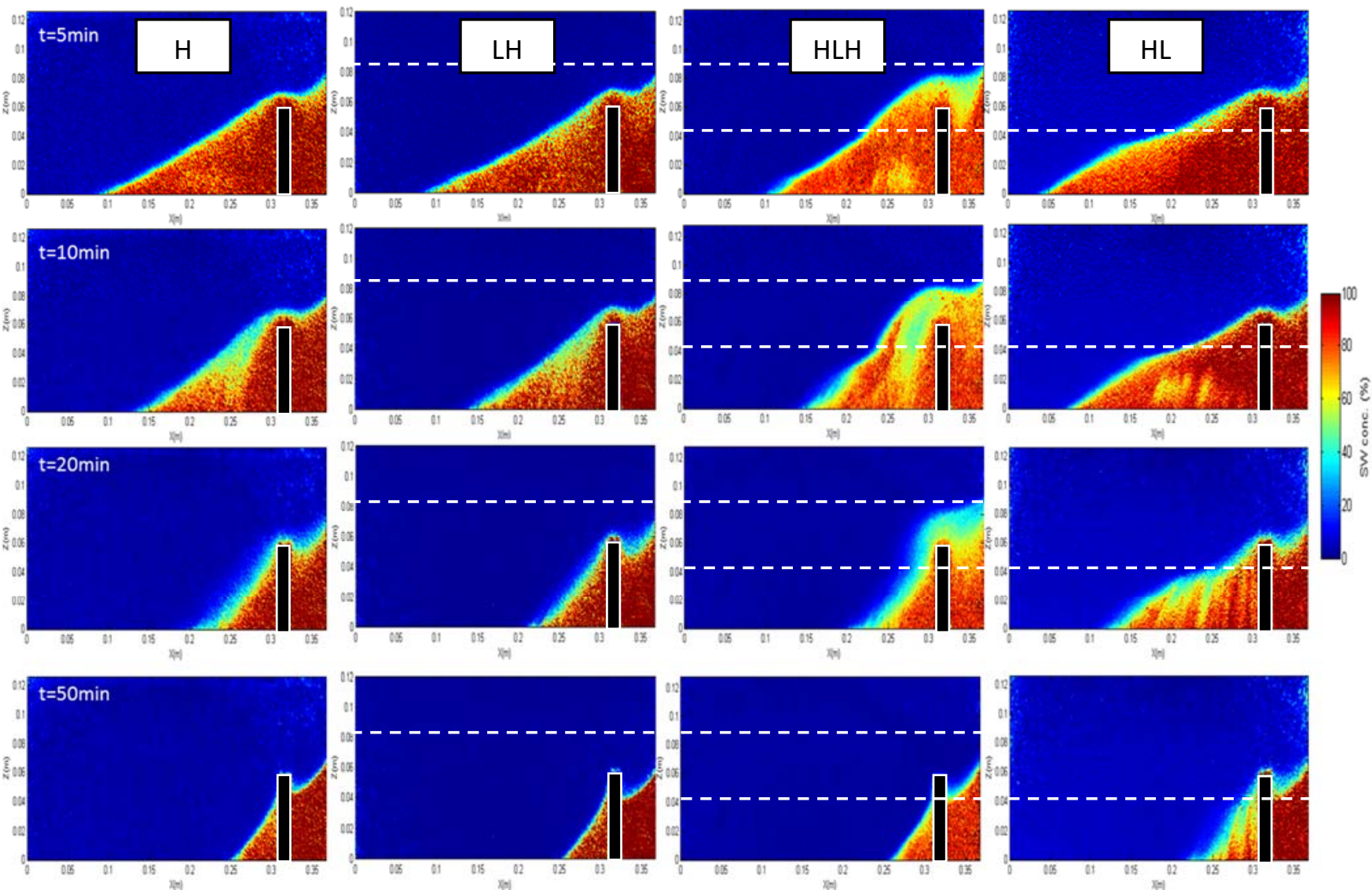

Figure 12 Transient experimental receding-wedge phase after returning the head difference back to $\mathrm{dh}=6 \mathrm{~mm}$.

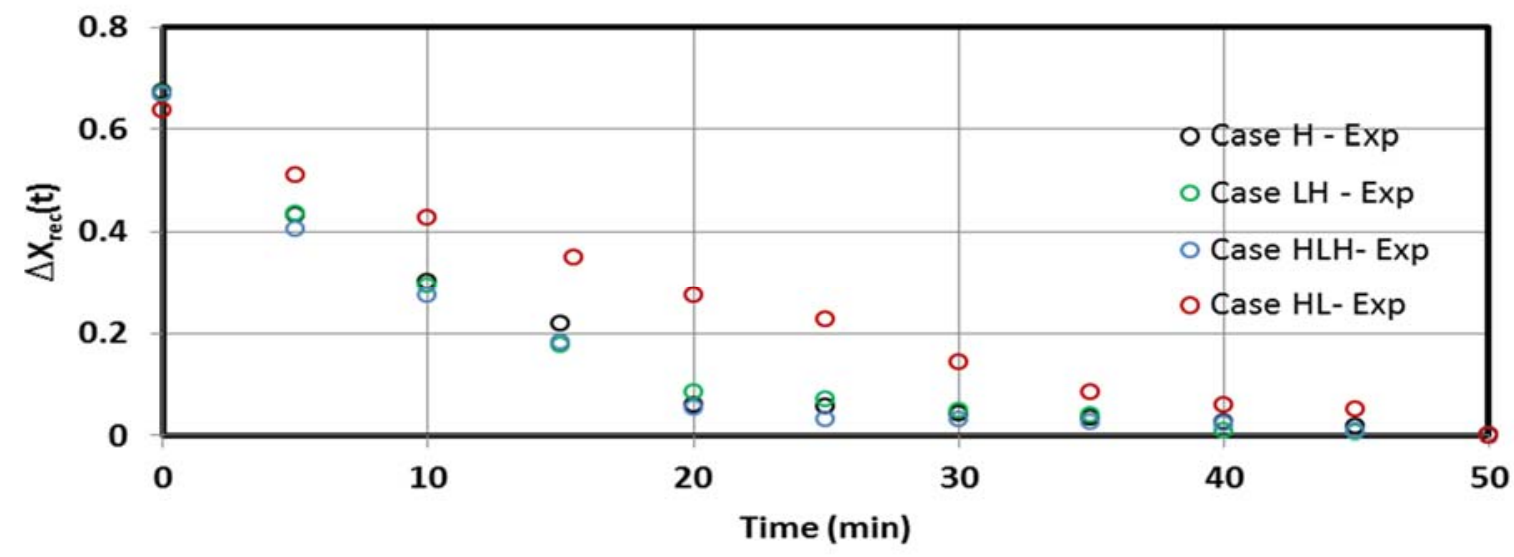

Figure 13 Transient experimental toe receding rates after resetting the initial head difference dh $=6 \mathrm{~mm}$

494 The migration rate of the receding wedge was analysed in all the cases and the results are

495 presented in Fig 13. The parameter $\Delta \mathrm{X}_{\mathrm{rec}}(\mathrm{t})$ was used to characterise the distance to be

496 travelled by the toe until its position when the receding motion saltwater plume became

497 steady forming a residual wedge on the landward side of the wall, i.e. at $\mathrm{t}=50 \mathrm{~min}$, such that 
$\Delta \mathrm{X}_{\text {rec }}(\mathrm{t})=\operatorname{abs}\left[\mathrm{X}(\mathrm{t})-\mathrm{X}_{\mathrm{f}}\right] / \mathrm{X}\left(\mathrm{t}_{0}\right)$; where $\mathrm{X}\left(\mathrm{t}_{0}\right)$ and $\mathrm{X}_{\mathrm{f}}$ are the toe lengths at $\mathrm{t}=0$ min and $\mathrm{t}=50$

$499 \min$, respectively. The small discrepancies at the initial condition $(\mathrm{t}=0 \mathrm{~min})$ are simply due to the minor differences of $\mathrm{X}\left(\mathrm{t}_{0}\right)$ upon the application of the inland head change. The data show that the migrating saline water was much slower in case HL, while relatively similar in the other cases. This was expected because the bottom low $\mathrm{K}$ layer slows the transit of the

503 freshwater flow in the lower part of the system, thereby preventing the effective upward lifting of saline water.

Table 6 Time required for complete cleanup of the freshwater zone $T_{\text {flush }}$

\begin{tabular}{|c|c|c|c|c|}
\hline Cases & Case H & Case LH & Case HLH & Case HL \\
\hline Exp & $135 \mathrm{~min}$ & $155 \mathrm{~min}$ & $160 \mathrm{~min}$ & $200 \mathrm{~min}$ \\
\hline Num & $117 \mathrm{~min}$ & $131 \mathrm{~min}$ & $137 \mathrm{~min}$ & $233 \mathrm{~min}$ \\
\hline
\end{tabular}

506

The complete cleanup of the freshwater zone required extending the test retreat time beyond 50 min. The freshwater zone was considered cleaned up when no saline water could be observable, even of low concentration. The time required for the saline water to be completely flushed from the freshwater zone $\mathrm{T}_{\text {flush }}$ was recorded in each aquifer setting (table 6). The presence of stratified layers generally prolonged the time needed for the residual saline water to be flushed out. Unexpectedly, the time for complete saltwater removal in case LH was

513 longer than the homogeneous scenario (15\% longer).

This rather counter intuitive finding may be the result of two opposed influential factors associated with the presence of an overlying low $\mathrm{K}$ layer. The first is the downwards channelling of the freshwater flow by the upper low $\mathrm{K}$ layer, which increases the flow

517 velocity in the lower part of the system and thus promotes the easier lifting of saline water.

518 The second factor is the reduction of the total freshwater inflow, which leads to a reduction of 
the forces required to lift the denser saline water upward back over the wall. As a result, the time needed for complete flushing of the saltwater is longer. Our results therefore suggest that the second factor has more impact on the ability of the subsurface dam to clean up the freshwater area from SWI contamination. This is clearly shown in table 7, which shows the influence of the top low $\mathrm{K}$ layer thickness $\mathrm{W}_{\text {top }}$ on the cleanup time. The data show that $\mathrm{T}_{\text {flush }}$ initially decreased with increasing values of $\mathrm{W}_{\text {top }}$ (for $\leq 20 \%$ ), mainly under the influence of the first process described above. For values of $\mathrm{W}_{\text {top }} \geq 20 \%$, the increasing values of $\mathrm{W}_{\text {top, }}$ which obviously caused further reduction of the total freshwater inflow, led to increasing values of Tflush, thus mainly under the influence of the second process.

Table 7 Effect of the thickness of the top layer $W_{\text {top }}$ on the flushing time. The values of $W_{\text {top }}$ are given as percentage of the saturated thickness of the homogeneous case $(h=136 \mathrm{~mm})$. The inflow rate $Q_{\text {in }}$ were recorded after the flushing was completed

\begin{tabular}{|l|l|l|}
\hline $\mathbf{W}_{\text {top }}(\mathbf{\% )}$ & $\mathbf{Q}_{\text {in }}\left(\mathbf{c m}^{\mathbf{3}} / \mathbf{m i n}\right)$ & $\mathbf{T}_{\text {flush }}(\mathbf{m i n})$ \\
\hline $10 \%$ & 14.6 & 127 \\
\hline $20 \%$ & 12.9 & 123 \\
\hline $30 \%$ & 11.4 & 126 \\
\hline $40 \%$ & 9.7 & 128 \\
\hline $50 \%$ & 8.2 & 150 \\
\hline
\end{tabular}

532 In case HL, the presence of the underlying low $\mathrm{K}$ layer induced a substantial delay in the

533 flushing time of the saline water, as expected. It took nearly $50 \%$ more time for the residual

534 saline water to be removed than the homogeneous setting. As explained above, this is because

535 the underlying low $\mathrm{K}$ layer in this setting slows the freshwater flow that faces the residual 536 saltwater wedge thus inhibits the effective upward lifting of saline flux. It is obvious that if 537 the thickness of the low $\mathrm{K}$ layer was increased, the flushing time would be considerably 538 increased, as this would not only cause a decrease in the total freshwater inflow, but it would 539 also induce a greater zone where the flow velocity would be considerably lower. In case HLH, 540 the freshwater flow at the crest is reduced by the middle layer low $\mathrm{K}$ layer, which partly 
compromises the landward-seaward transfer of saline flux above the wall. This can be seen in

542 Fig 12, where the transition zone above the crest of the wall is noticeably wider and the

543 wedge is more refracted relative to the homogeneous case. The impact of the low $\mathrm{K}$ layer is 544 nonetheless much lessened than in case HL, since in case HLH the freshwater is allowed to

545 flow freely along the aquifer bottom, where it is needed to initiate the lifting process.

546 The results show that the receding rate of saline water in the numerical model yielded very 547 good agreement with the experimental data in all the cases (Fig 14). The time required for 548 complete removal of saline water from the landward side of the wall was also reported in 549 table 6. The data show that it took relatively less time for the freshwater zone to be 550 completely cleaned up in the numerical model for all the cases. The numerical results 551 nonetheless confirm the negative impact the stratified layers has in prolonging the time 552 needed to clean up the freshwater zone, in agreement with the experimental observations. 553 These findings imply that the in cases of equivalent water table rise, the time required for the 554 residual saline water to be completely removed from a coastal aquifer system would be 555 substantially longer in presence of low permeability layers into the system, compared to an 556 idealized homogeneous aquifer system. In other words, the ability of subsurface dams to clean 557 up coastal aquifer from intruded saline water may be largely overestimated when neglecting 558 aquifer heterogeneity effect through the assumption of idealized homogeneous condition. 


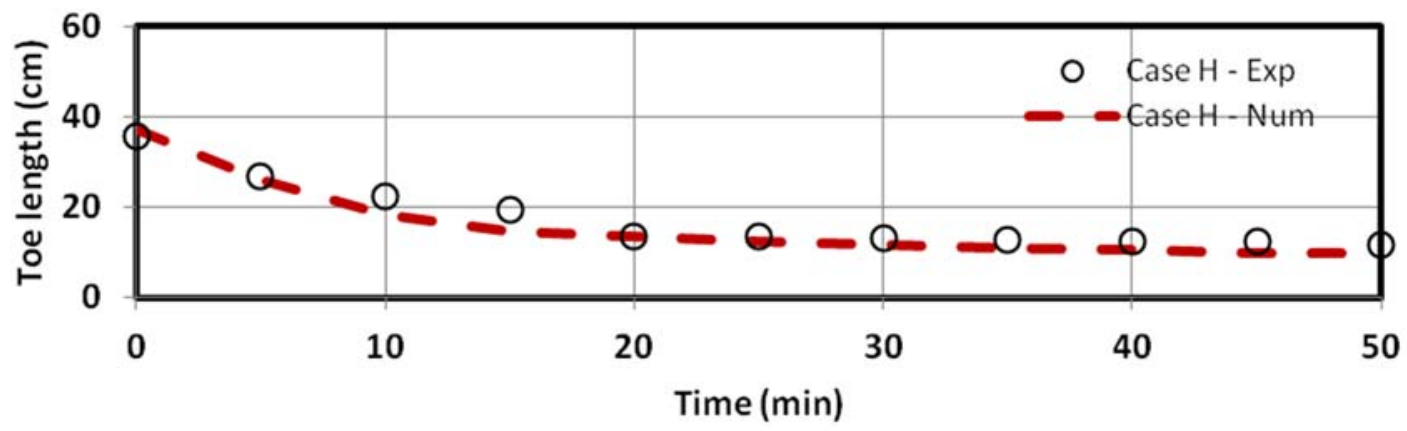

561
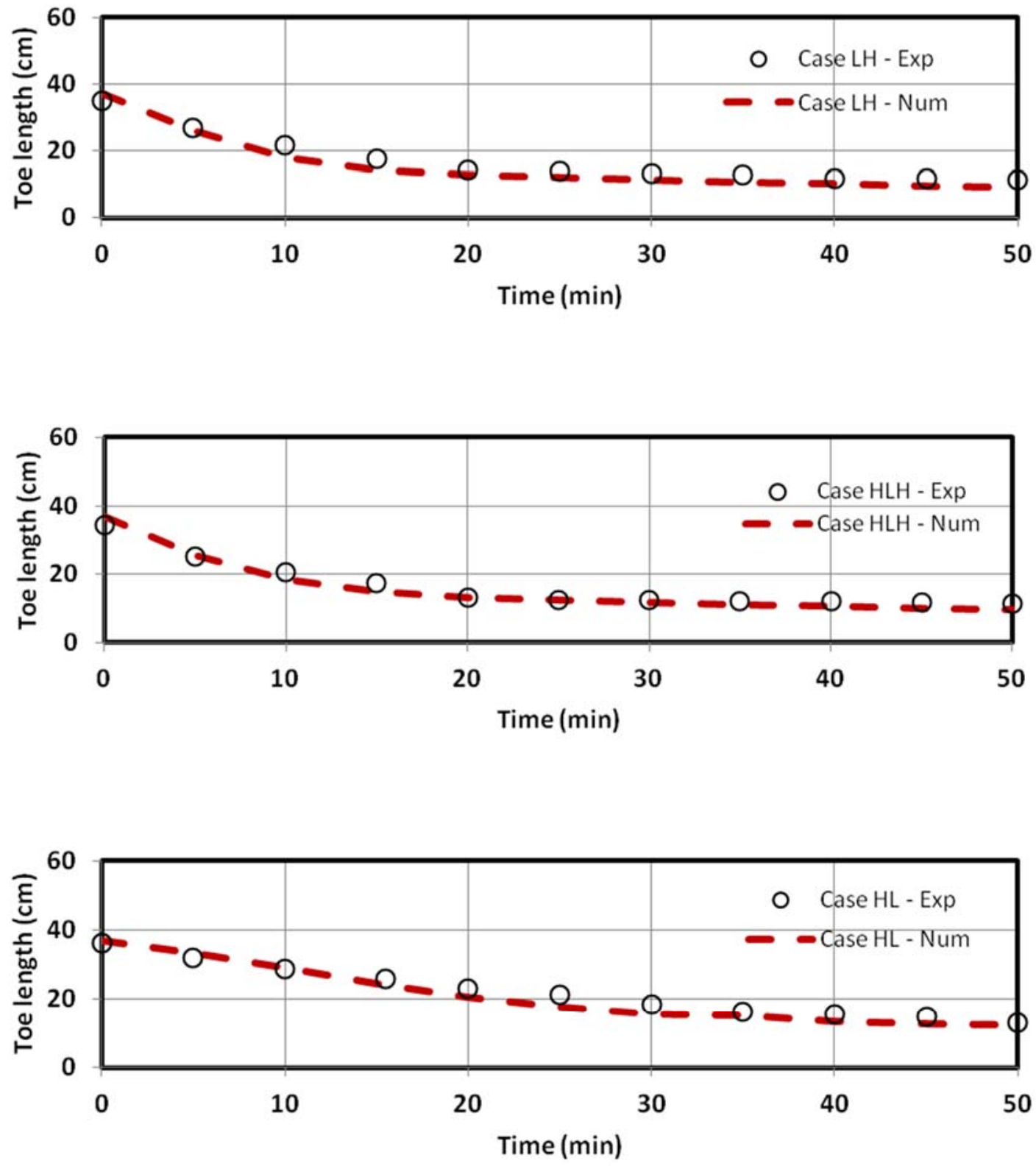

565 Figure 14 Comparison of the transient experimental and numerical toe length results of the 566 subsurface dam cases during the receding-wedge phase 
While Oswald et al. (2002) and Luyun et al. (2009) demonstrated that full removal of saline water by the inland freshwater flow is a plausible phenomenon in homogeneous system, the present findings provide for the first time strong evidence of the plausibility of such a natural cleanup process of contaminated coastal ground waters in strongly heterogeneous aquifer settings, with a rate of removal severely affected by the permeability and arrangement of the layers.

\section{Summary and Conclusions}

In this study, laboratory experiments and numerical simulations were used to assess the impact of layered heterogeneity on the ability of subsurface dams to control saltwater intrusion and to clean-up salinized coastal aquifers. Three layering configurations were examined, where a low K layer was located in the top part of the system (case LH), in the middle part of the aquifer as interlayer (case HLH) and at the bottom part of the system (case HL). An idealized homogeneous aquifer (case H) was also examined for reference purposes. The performance of subsurface dams was tested for their ability (1) to restrict the saline water intrusion mechanism during the advancing-wedge phase, and (2) to clean up the freshwater zone from residual saline water in the receding-wedge phase. The main findings of this investigation are:

- The existence of a low permeability zone in the upper part of an aquifer system generally enhanced the ability of subsurface dams to restrict SWI mechanism and lower the rate of saltwater spillage when it occurs, compared to the homogeneous setting. The overlying low $\mathrm{K}$ layer forces the freshwater to flow in the reduced spacing between the crest of the wall and the bottom boundary of this low K layer, which pushes the saltwater wedge downwards and impedes its building up. The results showed that the time taken for the aquifer to be contaminated was nearly twice longer than in the homogeneous case. 
- Conversely, the existence of low permeability zone in the lower part of the aquifer substantially weakens the ability of subsurface dams to retain SWI. The underlying low K layer caused magnitude of the flow velocity over the crest of the wall, which allowed an easier building up of saltwater wedge on the seaward side of the wall and caused the saline water to spill over the wall at even larger head difference compared to the homogeneous scenario.

- The natural cleanup of SWI-contaminated coastal aquifers was evidenced for the first time in heterogeneous (multi-layered) geological formations. The presence of stratified layers nonetheless prolonged the cleanup time compared to the homogeneous case to various degrees, depending on the stratification pattern.

- In presence of a low K layer at the upper part of the system (case LH), the time for complete saltwater removal was longer than the homogeneous scenario (about 15\%). This rather counter intuitive finding was because of the overall reduction of the total freshwater inflow into the aquifer associated with the presence of the low $\mathrm{K}$ zone, which induced a lessening of the forces required to lift the residual saline upward back towards the coastline.

- In case where a low permeability zone underlies the aquifer system (case HL), the time of completion of the cleanup process was at least about 50\% longer than in the homogenous scenario. In such setting, the underlying low $\mathrm{K}$ zone significantly slows the freshwater flow that faces the wedge and thus inhibits the effective upward lifting of saline flux on the seaward side of the wall.

The findings presented here are expected to have significant implications from water resources management prospective. Our results highlight the limitation of considering the common assumption of homogeneous condition when attempting to assess the performance of subsurface dams, which lead to large erroneous estimation of their ability to retain saltwater intrusion mechanism and clean-up previously contaminated coastal aquifers. 
Our results also suggest that the residual saline water trapped in the landward side of the wall

617

618

619

620

621

622

623

624

625

626

627

628

629

630

631

632

633

634

635

636

637

638

639

640

641

642

643

644

645

646

647

648

649

may be naturally removed from the freshwater zone without the need of mechanical removal techniques, despite the existence of such typical heterogeneous structures .The rate of removal would however be strongly dependent on the total groundwater inflow and the layering pattern, particularly the position of the low permeability layers in the aquifer. Other factors such as the dispersion within the aquifer and the density contrast may also considerably influence the cleanup time.

Although real world stratified coastal aquifers may exhibit much more complex layering patterns, the findings of the study provide a first insight on the impact of the expected disruption of flow dynamics imposed by typical layered structures on the performance of subsurface dams in controlling SWI.

\section{Acknowledgements}

The authors wish to thank Queen's University Belfast for supporting the research project through a PhD studentship accorded to the first author. Many thanks to the reviewers for their valuable comments that helped improve the manuscript.

\section{References}

Abarca Cameo, E. (2006), Seawater intrusion in complex geological environments, $\mathrm{PhD}$ thesis, TUC, Barcelona, Spain.

Abdoulhalik, A, and Ahmed, A (2017), The Effectiveness of Cutoff Walls to Control Saltwater Intrusion in Multi-Layered Coastal Aquifers: Experimental and Numerical Study. J Environ. Manage, 199, 62-73.

Abdoulhalik, A., Ahmed, A, and Hamill, G. (2017), A new physical barrier system for seawater intrusion control, J Hydrol, 549, 416-427.

Anwar, H. (1983), The effect of a subsurface barrier on the conservation of freshwater in coastal aquifers, Water Res. 17, 1257-1265.

Archwichai, L., Mantapan, K., \& Srisuk, K. (2005), Approachability of subsurface dams in the Northeast Thailand, In International conference on geology, geotechnology and mineral resources of Indochina, 28-30.

Ataie-Ashtiani, B., Volker, R.E., Lockington, D.A., 1999. Tidal effects on sea water intrusion in unconfined aquifers. J Hydrol., 216, 17-31.

Attanayake, P., Sholley, M. (2007), Evaluation of the hydraulic gradient at an island for lowlevel nuclear waste disposal, IAHS publication 312, 237-243.

Chang, S.W., Clement, T.P. (2012), Experimental and numerical investigation of saltwater intrusion dynamics in flux-controlled groundwater systems, Water Resour. Res., 48, W09527. 
650

651

652

653

654

655

656

657

658

659

660

661

662

663

664

665

666

667

668

669

670

671

672

673

674

675

676

677

678

679

680

681

682

683

684

685

686

687

688

689

690

691

Ferguson, G., Gleeson, T. (2012), Vulnerability of coastal aquifers to groundwater use and climate change, Nat Clim Change, 2, 342-345.

Goswami, R.R., Clement, T.P. (2007), Laboratory-scale investigation of saltwater intrusion dynamics, Water Resour. Res. 43, W04418.

Guo, W., Langevin, C.D., (2002) User's guide to SEAWAT; a computer program for simulation of three-dimensional variable-density ground-water flow.

Hanson, G., Nilsson, Å. (1986), Ground-Water Dams for Rural-Water Supplies in Developing Countries. Ground Water, 24, 497-506.

Hasan Basri, M. (2001), Two new methods for optimal design of subsurface barrier to control seawater intrusion, $\mathrm{PhD}$ thesis, The Univ. of Manitoba, Canada.

Kaleris, V.K., Ziogas, A.I. (2013), The effect of cutoff walls on saltwater intrusion and groundwater extraction in coastal aquifers, J Hydrol., 476, 370-383.

Ketabchi, H., Mahmoodzadeh, D., Ataie-Ashtiani, B., Simmons, C.T., 2016. Sea-level rise impacts on seawater intrusion in coastal aquifers: Review and integration. J Hydrol., 535, 235-255.

Lu, C., Chen, Y., Zhang, C., Luo, J. (2013), Steady-state freshwater-seawater mixing zone in stratified coastal aquifers, J Hydrol., 505, 24-34.

Luyun Jr, R.A. (2010), Effects of Subsurface Physical Barrier and Artificial Recharge on Seawater Intrusion in Coastal Aquifers, PhD Thesis, Kagoshima University, Japan.

Luyun Jr., R., Momii, K., Nakagawa, K. (2009), Laboratory-scale saltwater behavior due to subsurface cutoff wall, J Hydrol., 377, 227-236.

Michael, H.A., Russoniello, C.J., et al., 2013. Global assessment of vulnerability to sea-level rise in topography-limited and recharge-limited coastal groundwater systems. Water Resour.Res. 49, 2228-2240.

Morris, B.L., Lawrence, A.R., Chilton, P., Adams, B., Calow, R.C., Klinck, B.A. (2003), Groundwater and its susceptibility to degradation: a global assessment of the problem and options for management, United Nations Environment Programme.

Oswald, S.E., Scheidegger, M.B., Kinzelbach, W. (2002), Time-dependent measurement of strongly density-dependent flow in a porous medium via nuclear magnetic resonance imaging, Transp. Porous Media, 47, 169-193.

Robinson, G., Hamill, G., Ahmed, A.A. (2015), Automated image analysis for experimental investigations of salt water intrusion in coastal aquifers, J Hydrol., 530, 350-360.

Robinson, G., Ahmed, A.A., Hamill, G.A. (2016). Experimental saltwater intrusion in coastal aquifers using automated image analysis: Applications to homogeneous aquifers, J Hydrol. 538, 304-313.

Strack, O.D.L., Ausk, B.K. (2015), A formulation for vertically integrated groundwater flow in a stratified coastal aquifer, Water Resour. Res., 51, 6756-6775.

Strack, O.D.L., Stoeckl, L., Damm, K., Houben, G., Ausk, B.K., de Lange, W.J. (2016), Reduction of saltwater intrusion by modifying hydraulic conductivity, Water Resour. Res., 52, 6978-6988.

Sugio, S., Nakada, K., Urish, D.W. (1987), Subsurface seawater intrusion barrier analysis. J.Hydraul. Eng., 113, 767-779. 
692 Voss, C., Provost, A. SUTRA - a model for saturated-unsaturated, variable-density ground693 water flow with solute or energy transport (2010), US Geological Survey Water-Resources 694 Investigations report., 02-4231.

695 Werner, A.D., Bakker, M., Post, V.E.A., Vandenbohede, A., Lu, C., Ataie-Ashtiani, B., et al. 696 (2013), Seawater intrusion processes, investigation and management: Recent advances and 697 future challenges, Adv. Water Resour. 51, 3-26. 